\title{
Conditions of intergovernmental armaments cooperation in Western Europe, 1996-2006
}

\section{Journal Article}

Author(s):

Thiem, Alrik

Publication date:

2011

Permanent link:

https://doi.org/10.3929/ethz-b-000039122

Rights / license:

In Copyright - Non-Commercial Use Permitted

Originally published in:

European Political Science Review 3(1), https://doi.org/10.1017/S1755773910000251 


\title{
Conditions of intergovernmental armaments cooperation in Western Europe, 1996-2006
}

\author{
ALRIK THIEM * \\ Department of Social and Political Science, Center for Comparative and International Studies and Center for \\ Security Studies, ETH Zurich and University of Zurich, Switzerland
}

\begin{abstract}
Defence cooperation between Western European countries has increased considerably since the end of the Cold War. An analytical distinction can be made between political and economic cooperation, the latter having been neglected by political scientists. This study advances the debate on economic cooperation by identifying sources of variation in the European Union (EU)-15 countries' membership rate in cooperative armaments fora aimed at restructuring the demand side of European defence from 1996 to 2006. By combining six models from three different schools of thought, the risk of confirmation bias through intra-paradigmatic reasoning is reduced. At the same time, fuzzy-set analysis opens up the space for data-driven combination effects. Two distinct combinations form sufficient paths leading to high rates of membership. Most importantly, intentions to create collective defence technological and industrial benefits combine with trust in partners' ability and integrity to form an essential combination of conditions for governments to pursue cooperation on armaments.
\end{abstract}

Keywords: European Union; defence policy; armaments cooperation; fuzzy-set analysis

\section{Introduction}

Cooperation between governments has attracted substantial attention from political scientists. A particular instance in which academic interest has increased noticeably since the early 1990s has been cooperation between European Union (EU) member states in matters of defence (Howorth, 2007; Jones, 2007; Mérand, 2008). Almost 40 years after the abortive attempt to establish the European Defence Community, the Treaty on European Union (TEU) contained the first official reference to the progressive framing of a common European defence policy and encouraged member states to supplement this path with economic cooperation in the field of armaments.

European defence cooperation was thus to consist of two processes that would not have to be simultaneous, but have been considered complementary. The first concerns the political coordination of foreign policies among governments, whereas the second appertains to matters of economic cooperation in armaments

* E-mail: thiem@sipo.gess.ethz.ch 
research, development, production, standardization, procurement, or trade. However, while the political path has caught the academic limelight, economic aspects of that coordination have been neglected. This imbalance stands in need of redress for two reasons. First, an unprecedented consolidation of defence industries within and across national borders over the past 15 years has been accompanied by the emergence of a complex landscape of formalized intergovernmental fora (Schmitt, 2003: 12). ${ }^{1}$ While the former has represented a fundamental reorganization of the supply side, the latter is nothing less than a concerted effort to restructure the demand side of defence (Törnqvist, 2001). Second, the drive towards political cooperation has been inevitably linked to cooperation on armaments from the start, without which its benefits would not be fully realized. However, EU member states have responded differently to opportunities for restructuring the demand side. The question this study attempts to answer is why they have done so.

It has become a truism among political scientists that international phenomena cannot be fully comprehended without combining conditions found at the domestic and international level (Putnam, 1988; Evans, 1993; Moravcsik, 1997). This observation is specifically true for armaments cooperation, a policy domain that straddles the traditional demarcation line between the 'high politics' of security and the 'low politics' of economics (Taylor, 1990; Liberman, 1996; Mörth and Britz, 2004). Moravcsik (1993a, b), Kapstein (1991), Kocs (1995), Taylor (1982) and Tucker (1991), for instance, show how international cooperation has been shaped by 'competing imperatives' in conflicts of interest between governments and firms. In contrast, Legro (1996), Mawdsley (2000), and Mörth and Britz (2004) imply that any analysis of the interest formation process preceding intergovernmental cooperation is incomplete without allowing for the influence of culture. These authors illustrate that combinations of conditions can provide a fuller explanation, but they disagree about their composition and weighting. $^{2}$

Instead of narrow pre-selection, an alternative strategy is to associate a wider set of perspectives with the outcome, and let the empirics identify which single condition, or combination of conditions, fits the data best (cf. Koenig-Archibugi, 2004). As Wendt stresses in this regard, 'Realism does not have a monopoly on the ugly and brutal side of international life', so 'treating ideas and material conditions as separate but inevitably linked phenomena is a way of disentangling their respective effects' (Wendt, 1995: 76; 2000: 167). In like manner, Mearsheimer

\footnotetext{
${ }^{1}$ I use the term 'forum' in order to distinguish it from the more general meaning of an 'institution' or a 'regime', and the more specific meaning of an 'organization' (cf. Hasenclever et al., 1997: 10). For the purposes of this article, a forum is defined as a formalized intergovernmental agreement that may or may not be supported by a physical organizational structure.

2 To remain consistent with fuzzy-set terminology, a condition, or causal condition, represents an element of a configuration that is comparable to the concept of an independent variable. An outcome, or outcome condition is comparable to the dependent variable.
} 
(1990) holds that when the omission of Realist variables is corrected, liberal reasoning will collapse. There are two decisive advantages in using a more eclectic approach. First, the risk of omitting potentially important conditions that fall outside the realm of a single paradigm is reduced, which may lead to what econometricians call omitted-variable bias and psychologists refer to as confirmation bias. ${ }^{3}$ Although competing theories are often included, these do not always stand on an impartial analytical footing. As Checkel (2008: 120) puts it, '[i]f they are honest, most scholars will admit to having favourite theories'. Such treatments, however, are akin in effect to creating confirmation bias. ${ }^{4}$ Second, the possibility that different models can be combined opens up the space for distinct, combinatorial pathways to one and the same outcome, a situation referred to as 'equifinality', 'substitutability', or 'multiple conjunctural causation' (Ragin, 2000: 104; George and Bennett, 2005: 157; Starr, 2005: 358; Goertz, 2006: 63). ${ }^{5}$

This study contributes to the literature on armaments cooperation between European governments. It answers the question of which condition, or combination of conditions, may help explain variation in the rate of formal governmental membership in fora of armaments cooperation between 1996 and 2006. The explanatory side of the equation consists of six models (1) that balance different paradigms and therefore reduce the risk of bias, (2) whose respective conditions capture state-level characteristics, and (3) that are not mutually exclusive.

Scholars who underline the importance of domestic culture for international cooperation cite the degree to which a country is federalist in character (e.g. Jachtenfuchs, 2002; Wagner, 2002; Risse, 2005; Rittberger, 2005), an argument summarized under the constitutional-culture model. The homogeneity-trust model argues that cooperation may also be brought about by social interaction (e.g. Adler and Barnett, 1996; Wendt, 1999; Tonra, 2003; King, 2005). In contradistinction, Realists have emphasized the relative positionality of states in an international system that informs their policy decisions. Under the power-differential model, position affects the propensity to cooperate or not (e.g. Art, 1996; Jervis, 2005; Walt, 2005). The security-dependence model extends the argument by

\footnotetext{
${ }^{3}$ More precisely, omitted-variable bias is the positive or negative distortion in the estimated effect of an explanatory variable on the explained variable that arises when a correlated, excluded variable actually has an effect. Confirmation bias refers to a weak form of case building in which the failure to take the likelihood ratios of competing hypotheses into account may result in misjudgements of evidence (Nickerson, 1998).

4 This is not to argue that the more potentially relevant variables are included, the lower the risk of bias. In fact, even relevant control variables may induce more bias into coefficients of linear or generalized linear models than would have been induced if they had not been included (Clarke, 2005, 2009), and they create an exponentially growing number of potentially empty configurations in set-based methods.

5 The downside is that conditions have to remain at a rather unrefined level. This disadvantage can be eliminated in multiple-step optimization procedures, where hypothesis testing can proceed from a high level of aggregation to more refined set-ups once relevant 'rough' conditions have been identified. For a similar logic using remote and proximate conditions, see Schneider and Wagemann (2006). I will use the term 'model' throughout the text to describe any relationship between causal condition(s) and outcome.
} 
pointing out that national power capabilities are nugatory for a state's security if they are largely sustained by imported resources. This creates a potentially threatening situation in which disruptions open up windows of vulnerability (e.g. Grieco, 1988; Huntington, 1993; Waltz, 2000). When scholarship emphasizes groups of actors in the domestic arena, in contrast, the focus of attention is on their respective influence on the policymaking process. While the policy-responsiveness model argues that government policy is a function of domestic public opinion (e.g. Page and Shapiro, 1983; Erikson et al., 2002; Eichenberg and Stoll, 2003), the marketcompetition model stresses the role of business (e.g. Moravcsik, 1993a, b; Domhoff, 2002; Jacobs and Page, 2005).

Fuzzy-set qualitative comparative analysis (QCA) represents an appropriate method for implementing the approach laid out above, for reasons that will become clearer in the methodological section. But most importantly, from the viewpoint of theory-building, it allows the data to determine the combination that accounts best for the connection between conditions and outcome.

The article is structured around five sections. First, the outcome condition is introduced. Second, the six models are constructed in sufficient detail, and their operationalisation subsequently laid out in the third section. Fourth, the logic of fuzzy-set QCA is explained more fully, as it differs from traditional methods for hypothesis testing. And fifth, the results are presented, analyzed, and interpreted, followed by the conclusions.

\section{Intergovernmental armaments cooperation}

Even though post-war cooperative defence initiatives date back to the 1950s, the TEU marked the first time that official reference was made to the progressive framing of a truly common European defence policy. After the way had been cleared at St. Malo in 1998, the European Security and Defence Policy (ESDP) emerged. ${ }^{6}$ One of the most important elements in this process was defined as capability improvement through cooperation on armaments in order to make available the equipment necessary to fulfil the kind of missions envisaged by the Petersberg Tasks, and further specified in the Helsinki Headline Goal of 1999, the European Capabilities Action Plan of 2001, the 2010 Headline Goal of 2004, and the Capability Development Plan of 2008. The European Commission was in no doubt about the military benefits of such a course of action, particularly against the backdrop of contracting defence budgets, but also cautioned that the 'anachronic fragmentation of the defence markets in Europe' may lead to 'massive job losses and the disappearance of technological skills [...]' (European Commission, 1996: 3, 29). Cooperation reduces the wasteful duplication of overheads, such as research and testing, it generates economies of scale and learning, and thus contributes

\footnotetext{
${ }^{6}$ With the adoption of the Lisbon Treaty, the ESDP has been renamed the Common Security and Defence Policy.
} 
to the competitiveness of Europe's defence technological and industrial base. ${ }^{7}$ From an operational and economic perspective, the arguments in favour of armaments cooperation were therefore compelling (cf. Lorell and Lowell, 1995).

The TEU left the production, trade, and procurement of military goods and services almost entirely in the hands of national governments. Article 346 of the Lisbon Treaty (ex article 296 TEC), which codifies the exemption of armamentsrelated issues from the rules of the Common Market, is still regularly invoked (European Commission, 2007; Hartley, 2008). Nonetheless, on the supply side, the consolidation of defence industries increasingly shifted from domestic to cross-border activity during the 1990s, thereby promoting rationalization and integration on a European scale. On the demand side, governments have not only been cooperating on specific projects, but also have more generally aimed at putting joint procurement procedures, $R \& D$, and technical as well as legislative harmonization on a durable basis beyond individual equipment programmes.

In conjunction with Italy and Germany, France and the United Kingom established the Organisation Conjointe de Coopération en Matière d'Armement (OCCAR) in November 1996, following a Franco-German declaration in 1993 stating their intention to form a structure for administering collaborative defence equipment programmes (Hartley, 2006: 475). As OCCAR is a legal entity, it can sign contracts with industry on behalf of governments. Currently, seven projects are being managed, including the six-nation A400M airlift transport, the FrancoItalian Frégate Européenne Multi-Missions, and the German-Dutch Boxer armoured utility vehicle.

Another example of intergovernmental cooperation was the Letter of Intent (LoI), which was established by the Defence Ministers of France, Germany, Spain, Italy, Sweden, and the United Kingdom in July 1998. Initially, its main aim was to lay out the general basis for the restructuring of the West European defence industry, but later the emphasis shifted to the formulation of concrete measures for harmonizing military equipment, improving security of supply, increasing cooperation on research, and reducing legislative impediments (Mawdsley, 2008).

Other fora have a clear regional focus in addition to a functional one. In November 1994, Denmark, Sweden, Finland, and Norway established the Nordic Armaments Cooperation Agreement (NORDAC), which facilitates cooperative projects between their naval, land, and air forces in order to achieve financial, technical, and industrial benefits. ${ }^{8}$ The brief description of these three examples shows that armaments cooperation has not been confined to the ambit of EU

\footnotetext{
${ }^{7}$ Multinational cooperation on research is estimated to offer a 5:1 return on investment (UK Ministry of Defence, 2005: 26). Compared to national development costs $C_{n}$, the costs of $p$-lateral programmes $C_{p}=C_{n} \sqrt{p}$. Cooperation involves cost reductions, but generally no cost efficiencies.

${ }^{8}$ Regional agreements should not bias the results for two reasons. First, NORDAC is also open to non-regional countries. Second, the concept of regional cooperation is not exclusionary. Cooperative policies do not depend on geographical location. NORDAC was integrated into Nordic Defence Cooperation (NORDEFCO) in November 2009.
} 
treaties, and that the dimensions along which their expected benefits can be aligned are economic rather than political.

Common to all fora is the objective to achieve these benefits for their members. Even though conflicts over their distribution may impede practical effectiveness and lead to allocative inefficiency, participation, because it is of very low public visibility, testifies to governments' genuine intent to create practical collective gains rather than to join in political acts of rhetorical magniloquence. The fact that rates of membership vary thus begs the question as to why some governments have exhibited a propensity to enter into cooperation while others have stayed out. What factors account for this uneven pattern across Western Europe?

\section{Theoretical approaches and causal conditions}

The following section introduces six explanatory approaches. The arguments of the constitutional-culture model and the homogeneity-trust model follow a Constructivist pattern. In contrast, Realist thinking in international relations lies at the core of the power-differential model and the security-dependence model. Liberal accounts have been shaped by debates about the influence of public opinion on government policy under the policy-responsiveness model, and industrial interests under the market-competition model.

\section{Constitutional culture}

A number of works on European integration direct attention to a factor that draws on assumptions about the national collective identity of states. In the opinion of scholars espousing this perspective, a country's willingness to engage in projects of European cooperation can be understood as a function of its domestic constitutional tradition with respect to its embrace of federalist structures. Tracing the historical evolution of the European Parliament, Rittberger (2005) shows that the inter-state haggling over the complexion and functions of the nascent European institutions was influenced by national constitutional traditions, an argument Wagner (2002) extends to the 1990s. Similarly, Hooghe and Marks (2001: 157) find that the attitudes of Commission officials towards the issue of European governance can be predicted with some confidence based on the degree to which the country they come from has a federalist tradition. So, even officials exposed to environments in which the effect of national constitutional socialization should be expected to decrease in relevance seem to retain much of their initial mindset. Bulmer (1997) examines the degree to which Germany's federalist system has structured the EU's system of governance. The practice of solving domestic problems through power-sharing mechanisms has to a large degree informed German policy on European integration, which itself has become remarkably congruent with German federalist structures in many respects, the author holds. Risse (2005: 304) addresses Wiener's (2003) critique of Constructivism's awkward relationship 
with defence and security issues by arguing that states with a federalist tradition are more willing to communitarize foreign and defence policies, courtesy of their inherent preparedness to share sovereignty, and prefer cooperation to unilateralism. There is no reason to suspect that this logic should not be applicable to cooperation on armaments. Based on the constitutional culture model, it is hypothesized that:

HYPOTHESIS 1: EU member states with a tradition of federalist political authority show a high rate of membership in cooperative armaments fora.

\section{Homogeneity and trust}

Constructivist arguments on European integration have often been supported by literature on socialization, behavioural adaptation, and group formation, be it in the case of states (Wendt, 2000), officials (Hooghe and Marks, 2001), or national representatives (Lewis, 2005). They share the feature of 'a social process through which agent properties and preferences change as a result of interaction' (Checkel and Moravcsik, 2001: 220). Social interaction is related to behaviour because it entails a process of mutual convergence within groups of actors (Wendt, 1999: 82).

According to Aronson et al. (2007: 272), a group consists of 'two or more people who interact and are interdependent in the sense that their needs and goals cause them to influence each other'. 9 There is a particular characteristic present in groups that unites its members - homogeneity. This phenomenon has two facets to it, the first of which antedates group formation, so that what Feld (1982) has referred to as 'specific foci' bring together preferentially homogeneous sets of people with similar 'needs'. These needs may be founded on common characteristics or interests. The other facet then accompanies and post-dates it. Groups, once established, operate in such a way that further homogenization is encouraged. Hence, not only does an initial similarity in preferential homogeneity already exist prior to group formation, but the group consolidation process itself further amplifies tendencies towards more similarity (Levine and Moreland, 1990: 597).

Sometimes, the focus of the group is functionally rather than preferentially determined, so that the group formation process rests on the achievement of a common 'goal'. When individuals form a group or an existing group depends on the help of another group to complete a task, then this process increases cohesiveness between their members (Mullen and Copper, 1994).

Members of preferential groups benefit from a similarity-trust advantage as a result of norm congruence. In contrast, trust towards outsiders will only be developed if they are found to be either preferentially or functionally homogeneous and do not stand in competitive interdependence. Trust is understood as the 'willingness to rely on another's actions in a situation involving the risk of opportunism' (Williams, 2001: 378), based on expectations of the helpfulness, or at least harmlessness, of others' behaviour (Gambetta, 1988). These expectations

9 Emphasis added. 
lead to assessments of outsiders' ability and integrity, which will be more favourable if they are found to be either preferentially or functionally homogeneous (Williams, 2001). Ability is simply the 'group of skills, competencies, and characteristics that enable a party to have influence within some specific domain', whereas integrity is the trustee's adherence 'to a set of principles that the trustor finds acceptable' (Mayer et al., 1995: 717, 719).

Transposed from social psychology and organization science to the discipline of political science, Tonra (2003) and King (2005) suggest that the Common Foreign and Security Policy (CFSP) and the ESDP, respectively, be regarded as regimes that induce a convergence of expectations between the actors involved and a process that lets parties assess others' ability and integrity. The same holds true for the economic side of defence cooperation. The Swedish Ministry of Defence (2004: 19), for instance, only wants to enter into cooperation with 'the most important countries as regards the international skills we need for our equipment supply', while the UK Ministry of Defence (2005: 45) emphasizes mutual understanding and trust. Others, such as Adler and Barnett (1996), resuscitate the concept of 'security communities', which are characterized by a process of face-to-face interaction, a core of shared values and beliefs, and reciprocity. The 'thickness' of this process leads to the convergence of identity and behaviour via the number of interactions - the quantitative channel - as well as the intensity and duration of the interaction - the qualitative channel - so that 'shared identities [...] will produce a desire for military cooperation' (Adler and Barnett, 1996: 94). Based on the homogeneity-trust model, it is hypothesized that:

HYPOTHESIS 2: EU member states with high levels of preferential or functional homogeneity also show a high rate of membership in cooperative armaments fora.

\section{Power differentials}

Realism is often regarded as the touchstone of International Relations, the yardstick against which all competing theories must be measured at one point or another in order to pass muster (Waltz, 2000). For Realists, the fundamental goal of states is their survival through the prevention of relative declines in capabilities (Grieco, 1988: 498; Mearsheimer, 2001: 46), as they can never be sure whether today's friend will not be tomorrow's enemy (Waltz, 1959: 188). To this end, balancing and bandwagoning provide strategic policy options.

Balancing Theory has experienced a revival over the course of the 1990s, albeit in 'softer' versions de-emphasizing open military confrontation and armed conflict (e.g. Posen, 2006). Art (2006: 183) defines balancing as 'behaviour designed to create a better range of outcomes for a state vis-à-vis another state or coalition of states by adding to the power assets at its disposal, in an attempt to offset or diminish the advantages enjoyed by that other state or coalition'. Put differently, the process of balancing describes an (concerted) attempt by a weaker state (a group 
of weaker states) to prevent a rising power from assuming sole leadership, or of preventing a state that is already riding the crest of unipolarity from becoming a hegemon (Paul, 2004: 2). The emergence of European security and defence cooperation has provided a particularly fertile ground. Scholars espousing this perspective interpret the drive towards cooperation in defence within Europe as a manifestation of balancing on the part of the larger states against the United States (Art, 2004, 2006; Layne, 2003, 2006).

The concept of bandwagoning completes the picture. Following Walt (2005: 183), it is the tendency of a state to ally with rather than against the dominant side. Countries that are relatively close to each other in terms of power capabilities are more likely to balance, whereas countries whose differential is relatively large are more likely to bandwagon with the most powerful state to whose strength they feel attracted (Walt, 1985: 7).

Mearsheimer (1990), Art (1996), and Jervis (2005) suggest that small European states will seek to retain the security umbrella of the United States that has brought stability and peace to them. The weak states prefer to bandwagon with the United States rather than to team up with large European ones because not only have the Americans proven their benign intent over the course of the Cold War, but also the contribution of capabilities they could make to the balancing states does not off-set the gap that would still persist. The characteristic positionality of European states in relation to their neighbours and the United States should thus determine the willingness to cooperate or not. With regards to political cooperation, some quantitative evidence for this logic has been presented by Koenig-Archibugi (2004). Based on the power-differential model, it is hypothesized that:

HYPOTHESIS 3: EU member states with a low power differential in relation to the United States show a high rate of membership in cooperative armaments fora.

\section{Security and dependence}

The modern idea that economic interdependence fosters peace and understanding between states is often traced back to the works by Kant and Reiss ([1795]1970) and John Stuart Mill ([1865]2007). However, Realists have often cast doubt on the direct existence of such a causal arrow (Waltz, 2000; Mearsheimer, 2001). In fact, economic interdependence as a condition should enter the equation only once the provision and maintenance of power capabilities is sustained by sources generated through economic ties. Gains from trade interdependence are weighed against the disadvantages resulting from economic dependence, a situation that has often been referred to as the 'autarky-efficiency dilemma' (Moravcsik, 1991). It is argued that states would always prefer to be less dependent if their relative capabilities were not negatively affected (Waltz, 2000: 15). But states that are relatively independent economically are, Ceteris paribus, in a stronger position regarding the pursuit of their core interests than others (Huntington, 1993). As Waltz (2008: 204) notes, 
'[s]tates, if they can afford to, shy away from becoming excessively dependent on goods and resources that may be denied them in crises and wars'. Independence assumes especial salience with regard to security-related goods, as evidenced by the position of the UK Ministry of Defence (2005: 7), which aims to 'tell industry very clearly where, to maintain our national security and keep the sovereign ability to use our Armed Forces in the way we choose, we need particular industrial capabilities in the UK $[. .$.$] '.$

Drawing on historical case studies, Papayoanou (1997), for example, specifies the circumstances under which the degree of trade interdependence influences the capacity of state leaders to mobilize economic and political resources so as to counter perceived threats emanating from emerging powers. The author finds that economic interdependence has played a central role. When status-quo powers had strong economic ties with emerging powers, the risk of aggression by the latter was much more likely than when ties had been weak. Mearsheimer (1990: 45) points out that at the height of the oil crisis of 1973/4, US politicians seriously discussed seizing Arab oil fields by force of arms. At that time, the United States feared a significant decline in its capabilities due to its energy dependence. On the same note, the author maintains that the EU could only become increasingly economically interdependent because the US security umbrella allowed them to do so. From this perspective, peace and cooperation were not caused by growing interdependence, though that may superficially appear to be the case.

The security effects of trade dependence have also been examined by economists. Skaperdas and Syropoulos (2001) show that trade can have a negative security externality that outweighs its gains (cf. Gowa, 1989: 1246), and argue in conclusion that '[t]rade and economic interdependence can help resolve conflict, but it is naive and scientifically inappropriate to think that they are sufficient by themselves to do so' (Skaperdas and Syropoulos, 2001: 357). According to Realist logic, states that do not expose themselves to high levels of general economic dependence would be even less inclined to cooperate on armaments. Conversely, active traders do not seem to fear associated losses in their sovereign ability to use military capabilities, or simply cannot afford to act otherwise. Based on the security-dependence model, it is hypothesized that:

HYPOTHESIS 4: EU member states with a high degree of import dependence show a high rate of membership in cooperative armaments fora.

\section{Policy responsiveness}

Although public opinion has often been presumed and found to be a determining factor of government behaviour in democratic representation research (cf. Burstein, 2003), its role in the domain of foreign policy is still an area of heated debate (Holsti, 2004; Aldrich et al., 2006; Baum and Potter, 2008). Irrespective of the domain, the quality of democracy is often judged on the basis of how closely the policy output of governments matches the wishes of the majority of voters. 
In one of the most comprehensive studies, Page and Shapiro (1983) draw on data containing 357 instances of significant change in the policy preferences of US voters between 1935 and 1979. They find that large and sustained changes in public opinion, particularly on salient issues, did effectuate changes in policy at the local, state, and federal levels. Similar conclusions are reflected in the results of Monroe (1979, 1998). Opinion-policy consistency exists in about two-thirds of cases considered, with the highest level in foreign policy.

Nincic (1990) and Risse (1991) investigate the extent to which the United States, France, Germany, and Japan, respectively, reacted to the Soviet Union's foreign policy during the Cold War. Both authors also discover cycles of political behaviour that are in line with shifts in public opinion, but Risse (1991: 510) adds that the precise effect was conditioned by domestic constitutional structures as the intervening variable, a causal combination likewise alluded to by Soroka and Wlezien (2005). More specifically, Hartley and Russett (1992), and Bartels (1991) find that US military spending is linked to public demands. A sizeable effect is also found by Wlezien (2004), Soroka and Wlezien (2005) in the case of the United Kingdom, and by Eichenberg and Stoll (2003) in relation to the United Kingdom, France, and Germany.

Kernic et al. (2002: 21) hold that researchers have not yet given sufficient attention to the influence of public opinion on matters of security and defence integration in Europe. This neglect has been unwarranted, as 'public opinion represents a strategic variable of primary importance' (Kernic et al., 2002: 39). Defence is an important and expensive public good. The opinion of voters, who are also funding the defence budget in their capacity as taxpayers, may therefore have an impact on the armament policies of their governments. At least with respect to the ESDP, Eichenberg (2000: 174) concludes that 'European leaders are acting in a way that has long been consistent with domestic opinion'. Based on the policy-responsiveness model, it is hypothesized that:

HYPOTHESIS 5: EU member states with high public support rates for European defence cooperation show a high rate of membership in cooperative armaments fora.

\section{Markets and competition}

Drawing on data collected from 1974 through 2002, Jacobs and Page (2005) find evidence that in the United States, the influence of the public on defence policy is dwarfed by that of business. When it comes to business interests in relation to defence cooperation between EU member states, the literature on European integration has, however, as yet been rather silent.

In general, states have two main options in the procurement of military capabilities. First, they can purchase equipment externally. Those European countries that are members of NATO have imported between $20 \%$ and $32 \%$ of their defence equipment from the United States between 1987 and 1999 (Kapstein, 2002: 147). Portugal and Greece possess only a very weak arms industry and therefore have to 
import major systems from abroad (Barros, 2002). In export markets, global competition between large defence companies is intense because many primary systems are so expensive that only a few companies are able to develop them at a competitive cost, and buyer countries often require immense offsets for large-scale purchases. ${ }^{10}$ US firms in particular have gained much ground in comparison to their European rivals in this respect, not least because early consolidation developments in the 1990s have given them a post-Cold War first-mover advantage (Hayward, 2001; Crollen, 2003; Schmitt, 2003). However, export markets are key to the survival of European producers (Moravcsik, 1993a, b; Neal and Taylor, 2001).

Second, countries can procure the material they need domestically, and this is still standard practice in most large European countries (Cornu, 2001: 71; Keohane and Valasek, 2008: 36). Due to security reasons, balance of payments considerations, and concerns about technological advantage, governments want to retain a say in the activities of national armaments producers. At the same time, they have an interest in their national champions being able to create export opportunities for their products, thereby increasing capital investment at home and lowering the cost of maintaining indigenous capabilities. This presupposes that the country possesses a sizeable, and therefore internationally competitive, defence industry. From an economic viewpoint, the creation of export opportunities through cooperation is thus a win-win situation for governments and armaments companies. All national markets in Europe without exception are too small to generate adequate economies of scale (James, 2001: 102). As a result, the consolidation process within the European defence industry has been driven by the desire for size (Schmitt, 2000: 26-28). Firms are increasingly trying to capture foreign market shares by acquisitions that either integrate their operations vertically, thereby increasing technological expertise and revenue through the internalization of profitable subsystems, or horizontally, so as to enhance the transferability of managerial skills and the differentiation of products (Hayward, 2001: 120). Given governments' stakes in their defence technological and industrial base, cooperation on armaments provides a way to facilitate this process in the pursuit of collective benefits from cross-border consolidation. Based on the market-competition model, it is hypothesized that:

HYPOTHESIS 6: EU member states with a highly competitive domestic defence technological and industrial base show a high rate of membership in cooperative armaments fora.

This section has presented the six hypotheses to be tested. While each was formulated in such a way as to let their respective causal conditions explain the outcome individually, combinations of conditions are not precluded. On the contrary, conjunctural rather than individual causation is expected.

\footnotetext{
${ }^{10}$ Offsets are direct or indirect industrial compensation arrangements required by foreign governments or foreign firms as a condition of the purchase of defence goods or services. The financial scope of these arrangements varies, but often exceeds the procurement contract value.
} 


\section{Operationalization and data sources}

Some of the conditions that operationalize the hypotheses derived from the six models have become widely accepted. Others, however, have only recently been introduced to the discipline or have not yet been applied in this context. Condition labels are given in parentheses. ${ }^{11}$

\section{Membership rate (membership)}

The outcome condition is a monadic count of membership in formal intergovernmental agreements on armaments cooperation. In order to qualify as an instance under this definition, the agreement's main purpose had to be economic rather than political. This includes the standardization of military equipment, joint research, development and production activities, joint procurement mechanisms, trade-related legal harmonization, or any combination thereof. The agreements included are the European Air Group, the European Defence Agency, LoI, NORDAC, OCCAR, the Western European Armaments Group, and the Western European Armaments Organisation.

\section{Constitutional-culture model (federalism)}

The constitutional culture model uses the Regional Authority Index in order to measure the degree to which a country's domestic constitutional setup is federalist in character (Hooghe et al., 2008; Marks et al., 2008). It is derived from eight competencies of regional government, namely institutional depth, policy scope, fiscal autonomy, representation, law-making, executive control, fiscal control, and constitutional reform.

\section{Homogeneity-trust model (homogeneity)}

Constructivists have often been criticized for a lack of transparent measures. As 'Constructivists regard international structures to be social structures' (Ruggie, 1998: 879), participation in multinational military missions should operationalize such a structure transparently. States may develop, through preferential homogeneity in the motive for conducting the mission, or functional homogeneity in pursuance of a common goal, the degree of trust in others' ability and integrity that is required to enter into further cooperation in more sensitive areas such as armaments cooperation. Being embedded in these structures creates opportunities that allow participants to 'screen' these qualities. ${ }^{12}$ Therefore, the homogeneity-trust model is operationalized through bilateral interaction scores based on all UN and NATO military missions conducted between 1996 and 2006. Each EU country can

\footnotetext{
11 The codebook and data set with all base variables and fuzzified conditions are available from the author on request.

${ }^{12}$ Functionalism would reverse the argumentation, and hypothesize that the efficient conduct of joint missions necessitates armaments cooperation in order to guarantee standardized, or at least interoperable, equipment. However, illustrative case study research has shown that more often the opposite results because operational requirements rarely overlap (e.g. Lorell and Lowell, 1995).
} 
have up to $14 \mathrm{EU}$ partners per mission-year. The higher the score, the thicker the interaction process, and the larger the potential for trust development. ${ }^{13}$

\section{Power-differential model (power)}

The Correlates of War project's Composite Index of National Capabilities (CINC) has become widely accepted as an indicator of power (e.g. Geller, 1993; Maoz, 2004; Sweeney and Fritz, 2004). ${ }^{14}$ It incorporates an industrial, a military, and a demographic dimension, translating a state's score into a share of the international system (Singer et al., 1972; Singer, 1988). For constructing a measure that is valid in the EU-US context, each state's absolute component was converted to a share of a subsystem comprising only the EU-15 plus the United States. As the CINC does not cover all relevant years, a new index based on the same structure was computed using data on military expenditure in constant 2005 US\$ (Stockholm International Peace Research Institute, 1997-2007), military personnel (International Institute for Strategic Studies, 1997-2007), total population, urban population, and energy use in kilograms of oil equivalent (World Bank, 2008), as well as steel production figures (World Steel Association, 2009).

\section{Security-dependence model (dependence)}

The concept of economic dependence has been studied from two perspectives based on the inclusive concept of interdependence. The first is the economist's view, the second is that of International Relations Theory (Baldwin, 1980; Wallace, 1986). In the latter, the notion of interdependence has been applied to capture the concept of import vulnerability. Therefore, scores are computed by dividing current account debits of goods and services by GDP.

\section{Policy-responsiveness model (support)}

The data on national public opinion about cooperation in defence is taken from the Eurobarometer Survey Series 1995-2005. The question asked was: 'For defence and foreign affairs, do you think that decisions should be made by the (Nationality) Government, or made jointly within the European Union?' Public support scores take the percentage figure for those preferring cooperation minus the percentage figure for those being against it. In order to account for response delay, public opinion is lagged by 1 year, a value work on policy responsiveness has found to be reasonable (e.g. Eichenberg and Stoll, 2003; Jacobs and Page, 2005; Soroka and Wlezien, 2005).

\footnotetext{
13 The indicator only captures the number of interactions - the quantitative channel, but not the intensity of each interaction - the qualitative channel. Contributions that are largely symbolic rather than substantial may not have the same effect, and may well lead to loss of trust in the case of unfulfilled expectations, but they do not invalidate the logic of trust development as a result of preferential or functional homogeneity.

${ }^{14}$ Others have advocated GDP instead (e.g. Organski and Kugler, 1980; de Soysa et al., 1997; Wohlforth, 1999).
} 


\section{Market-competition model (competitiveness)}

Average defence company size is the indicator for the competitiveness of a country's domestic armaments industry. It is computed by summing up the arms sales of all defence companies listed by the Stockholm International Peace Research Institute based on size, and divides it by their number, reflecting an average ability to capture export market shares and acquire foreign companies (Stockholm International Peace Research Institute, 1997-2007). All current dollar sales figures have been converted to constant 2000 US\$.

\section{The fuzzy-set QCA approach}

The core idea behind QCA is that most social science theory is based on set relations, which are always asymmetric, as opposed to correlation-based methods, which are inherently symmetric. For example, the hypothesis that some causal condition $x_{1}$ led to outcome $y$ has two implications. First, the fact that $y$ was also brought about by some other causal condition $x_{2}$ does not invalidate the initial hypothesis. In set-relational terms, $x_{1}$ is a subset of the set of conditions that led to $y$. Second, the connection between $x_{1}$ and $y$ is asymmetric. Were one to investigate the correlation between conditions and outcome, the fact that $x_{2}$ also led to $y$ would undermine the correlation between $x_{1}$ and $y$, although this was not part of the original argument.

The verbal nature in which most social science theory is formulated, however, entails explicit connections between causes and outcome that require the decomposition of correlational statements into set relationships. This can be achieved in two ways. The first proceeds from the existence of an outcome shared by the units of analysis to the shared conditions hypothesized to be causally connected. Here, the outcome is a subset of the larger set of cases with the same causal conditions, and is thus suitable for tests of necessity. The second is to proceed from shared causal conditions of cases, or their combination, to a shared outcome. This strategy is consistent with arguments about sufficiency, where instances of the causes are a subset of instances of the outcome (Ragin, 2008). Expressed in set-relational language, this article tests whether any of the six individual conditions, or some combination thereof, represents a sufficient causal path to a high rate of membership in cooperative armaments fora.

While set relations provide the logic, the idea of fuzziness extends them in ways useful for social research. The social sciences are often described as 'soft' because they deal with concepts marked by imprecision and uncertainty. Fuzzy sets differ from conventional probabilistic thinking in that they substitute uncertainty associated with randomness by uncertainty associated with characteristic imprecision (Clark et al., 2008: 31). A fuzzy set $A$ is defined by a set of ordered pairs, so that,

$$
A=\left\{\left(x, \mu_{A}(x)\right) \mid x \in A, \mu_{A}(x) \in[0,1]\right\}
$$


where $\mu_{A}(x)$ is the membership function that specifies the degree $\mu_{A}$ in the interval between 0 and 1 to which every $x \in A$ belongs to $A$. Those elements with $\mu_{A}=1$ have full membership in $A$, whereas those with $\mu_{A}=0$ have full non-membership. At $\mu_{A}=0.5-$ the cross-over that determines whether a case is more in $(>0.5)$ than out $(<0.5)$ - set membership is most ambiguous. In this sense, a fuzzy-set membership score can more precisely be regarded as a continuous measure, purposefully calibrated along three thresholds so as to match the logic of the underlying concept in a qualitative as well as a quantitative way (Ragin, 2008: 30). The membership function translates all elements of the base variable into fuzzy-set membership scores. ${ }^{15}$ In order to fuzzify all base variables, conditions, and outcome, I use the logistic function

$$
\mu_{A}(x)=\frac{1}{1+\mathrm{e}^{-x}}
$$

where $x$ is the $\log$ odds of membership scaled in relation to the cross-over. ${ }^{16}$ Thresholds for full non-membership, the cross-over, and full membership were set at $\mu_{A}=0.05, \mu_{A}=0.5$, and $\mu_{A}=0.95$. This was not implemented in a mechanistic fashion. When assigning membership scores to longitudinal data, it is important to distinguish between base variables in which quantitative trends shift the qualitative meaning of membership scores and those where they do not, since trends in the measures of tendency or spread used for calibration may lead to inconsistencies between the fuzzified conditions and the qualitative meaning of their underlying concepts. A recalibration may therefore be required. ${ }^{17} \mathrm{~A}$ net public support rate of $0 \%$, for example, remains the cross-over in which the indicator is at its most ambiguous level. When politicians do not perceive public pressure in either direction, they have no incentive to act. Trends in the range or central tendency of the base variable are not qualitatively linked to set membership scores, and thresholds are externally defined. Conversely, country membership rates in armaments fora tend to grow over time. This necessitates a re-calibration of membership scores. Here, thresholds are defined internally. Re-calibrations were implemented for the outcome and all conditions except support and dependence. ${ }^{18}$

15 The process is often referred to as calibration or fuzzification.

16 This is the standard membership function implemented in the fsQCA software by Ragin et al. (2006). For details of the calibration procedure, see Ragin (2008). Other functions, such as the cumulative distribution of the uniform density have also been used (e.g. Koenig-Archibugi, 2004). However, they are not flexible enough as any two non-identical thresholds will define the fuzzy set.

17 The logic is similar to the de-trending of time series. However, instead of removing the trend directly, cut-off values are re-calibrated in line with changes in the base variable whose fuzzification at initial thresholds would decrease the level of consistency with the qualitative meaning of the fuzzy set label.

18 All base variable values underlying the thresholds for full non-membership $\alpha_{\mathrm{NM}}$, cross-over $\alpha_{\mathrm{CO}}$, and full membership $\alpha_{\mathrm{FM}}$ are provided in the Appendix. 


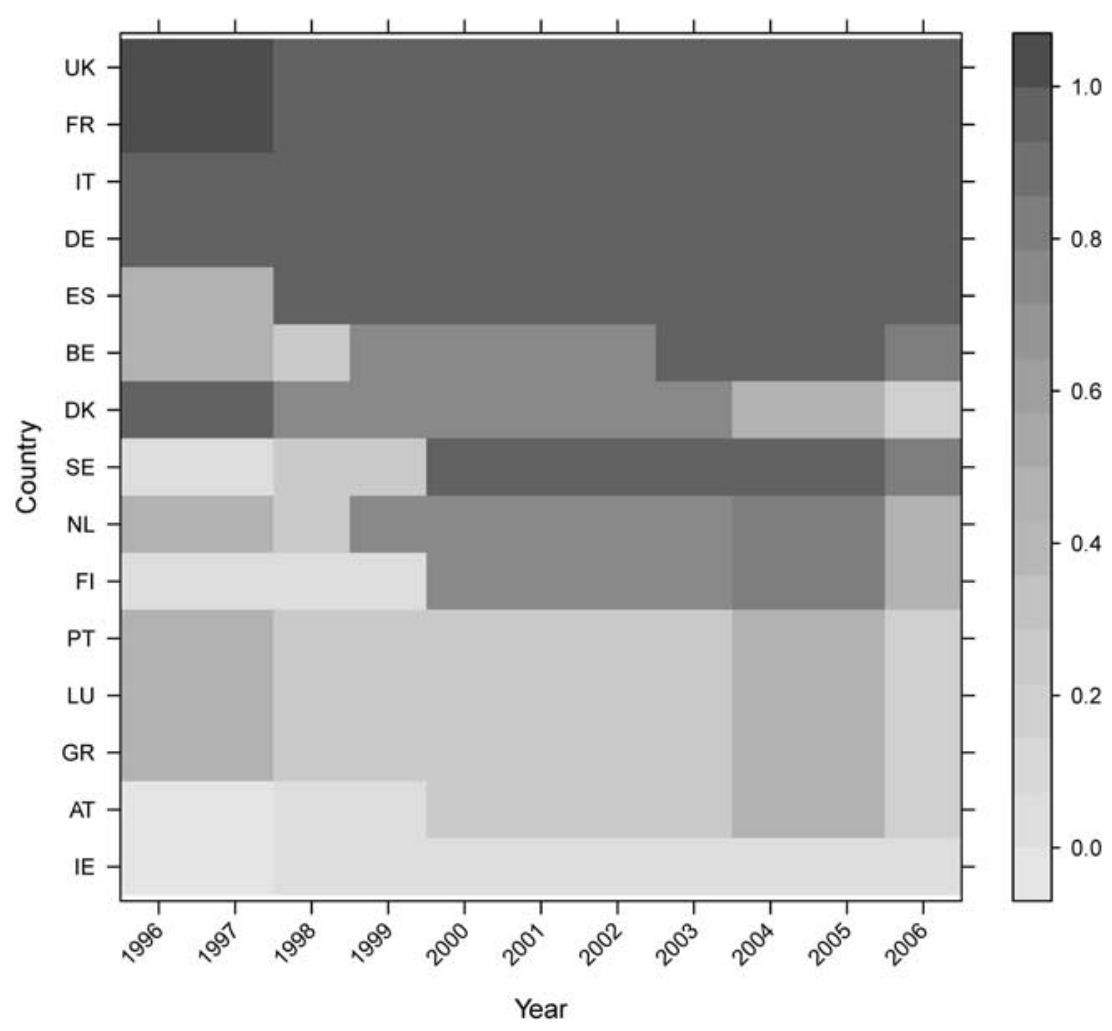

Figure 1 Membership scores in a set of countries with high rate of forum Membership

\section{Analysis and results}

The data set contains 165 observations. Figure 1 presents the fuzzified outcome set in a level plot ordered according to membership score row sums across years. Darker panels indicate high membership, whereas brighter panels indicate low membership. ${ }^{19}$ At the top are the United Kingdom, France, Germany, Italy, and Spain, followed by Belgium, Denmark, Sweden, the Netherlands, and Finland, with a majority of membership scores still exceeding the cross-over.

Figure 2 presents the respective membership scores for each condition, country, and year. The pattern of shading shows pronounced temporal fluctuations for homogeneity (2b), support (2e), and competitiveness (2f). Conversely, structural conditions that are expected to remain relatively stable, such as federalism (2a), show only minor shifts or even none at all.

${ }^{19}$ It is important not to confuse membership scores, which denote the degree of belonging to a fuzzy set, and membership rate, which is the label of the outcome condition. 
(a)

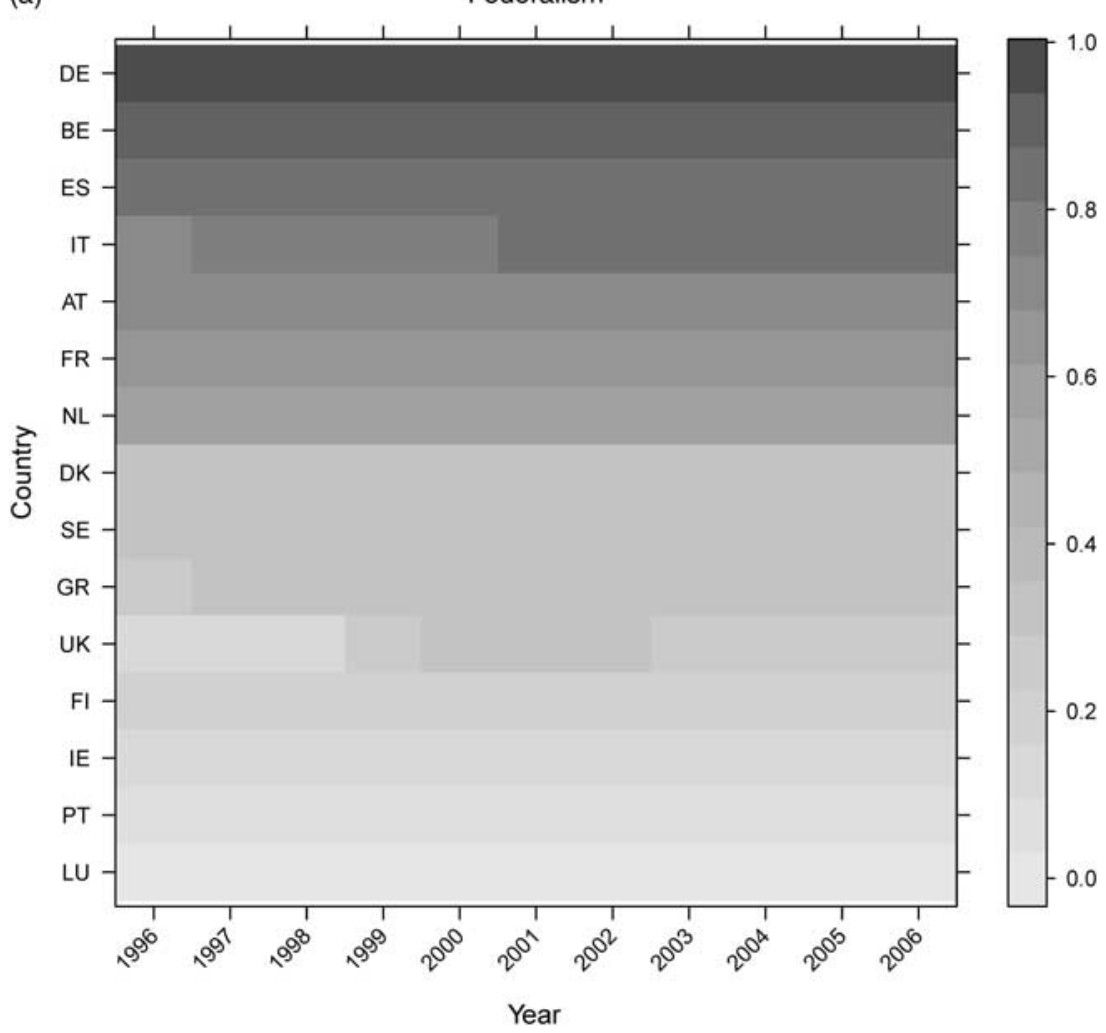

Figure 2 Fuzzy-set membership scores of causal conditions

The results of the minimization procedure are presented in Table $1 .^{20}$ At a frequency cut-off of six cases and a consistency threshold of $80 \%$, two distinct pathways to the outcome have been found under the intermediate solution, and two under the parsimonious solution. ${ }^{21}$ In none is evidence found for the existence of balancing or bandwagoning behaviour as argued by Art (2006), Layne (2006), or Jervis (2005). I will assess the intermediate solution first. ${ }^{22}$ Following standard set

${ }^{20}$ Although all hypotheses imply set relations of sufficiency between the condition and the outcome, tests for necessity were performed. Only homogeneity had a significant consistency level of $86 \%$. An analysis of sufficiency using asymmetric coding was not performed. Despite theoretical benefits, not having a low membership score to produce the outcome is not part of the above-formulated hypotheses.

21 A partial truth table is provided in the Appendix. The frequency cut-off determines the minimum number of cases that have to fall into a specific combination of conditions. At a cut-off of six, $86 \%$ of cases are captured. The number of causal combinations is an exponentially growing function of the number of conditions. With six conditions, there are $2^{6}=64$ different combinations. Consistency provides a measure of how well the results match the subset relation for sufficiency, and is evaluated using the following formula: Consistency $\left(X_{i} \leqslant Y_{i}\right)=\sum\left[\min \left(X_{i}, Y_{i}\right)\right] / \sum X_{i}$.

22 Simplifying assumptions: present $=$ federalism, homogeneity, dependence, support, competitiveness; absent $=$ power. 
(b) Homogeneity

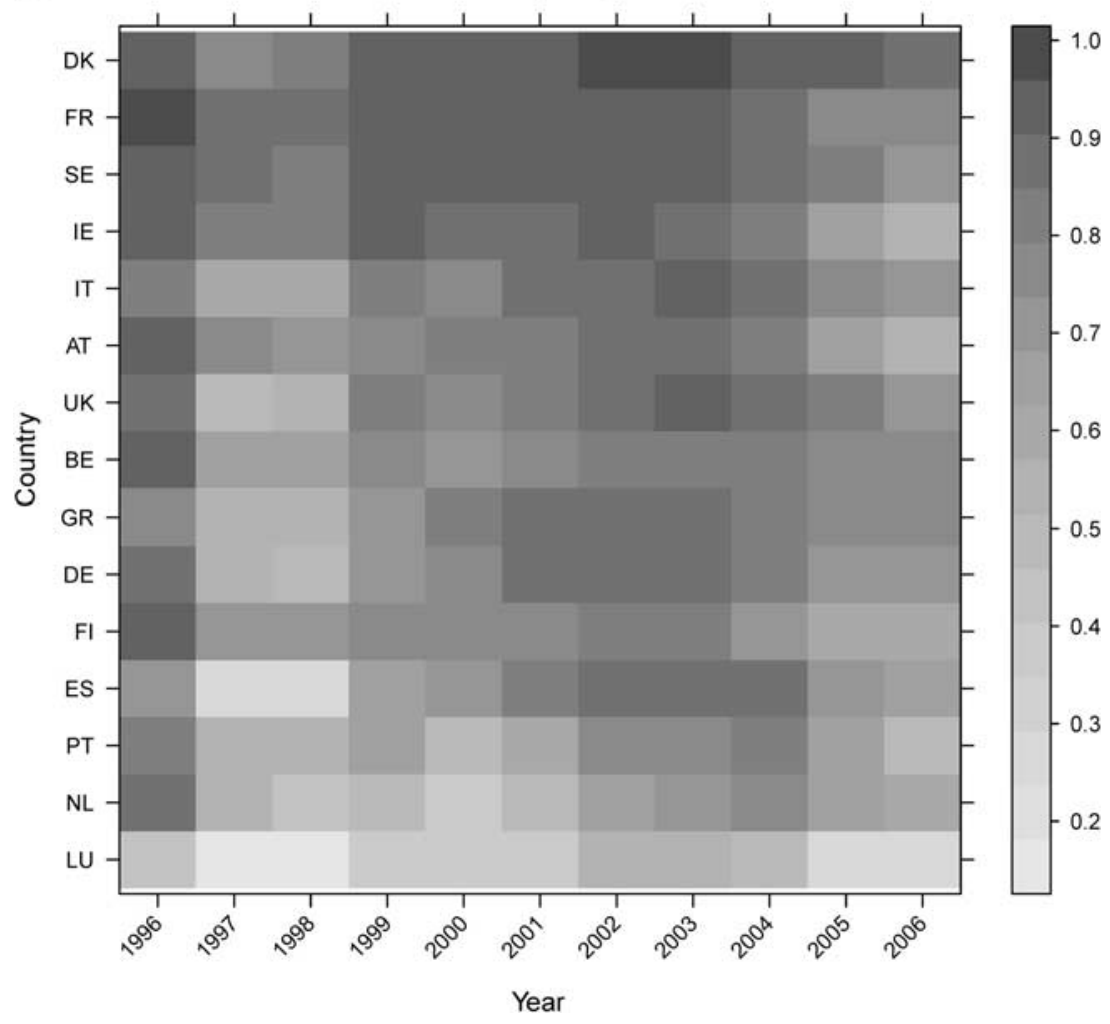

Figure 2 Continued

notation, the symbol ' $\cap$ ' denotes intersection and takes the minimum value in combinations of sets, ' $U$ ' stands for union and takes the maximum value, and ' $\subseteq$ ' indicates the subset relation. ${ }^{23}$ The two paths are the following with:

(Dependence $\cap$ support $\cap$ homogeneity $\cap$ federalism $) \cup$

(Competitiveness $\cap$ homogeneity) $\subseteq$ membership

The first path intersects the security-dependence model, the policy-responsiveness model, the homogeneity-trust model, and the constitutional culture model, while the second integrates the market-competition model with the homogeneity-trust model. In the subsequent discussion, I will refer to the former as 'Complex Predisposition', denoted by CP. It combines specific structural conditions that are relatively time invariant, such as a country's constitutional culture, and may also be responsible for similar state policy choices in other domains, with factors that

${ }^{23}$ More precisely defined, the intersection $C$ of two fuzzy sets $A$ and $B$ of $x$ is given by $C(x)=$ $\min [\boldsymbol{A}(x), \boldsymbol{B}(x)]$. The union $\boldsymbol{C}$ of two fuzzy sets $\boldsymbol{A}$ and $\boldsymbol{B}$ of $x$ is given by $\boldsymbol{C}(x)=\max [\boldsymbol{A}(x), \boldsymbol{B}(x)]$. A fuzzy set $\boldsymbol{A}$ is a subset of another fuzzy set $\boldsymbol{B}$ if for all $x, A(x) \leqslant B(x)$. 
(c)

Power

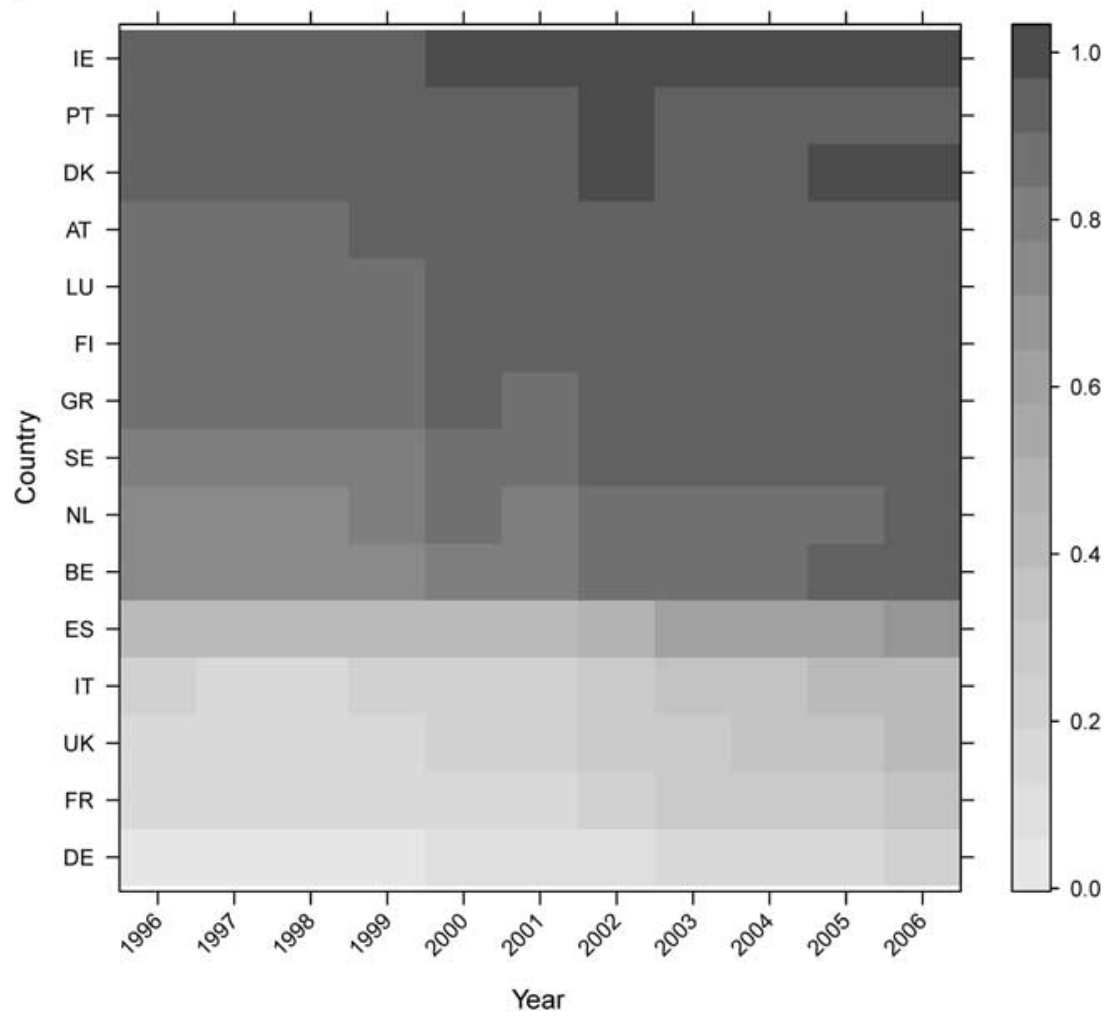

Figure 2 Continued

have a more immediate bearing, such as public support. The latter will be referred to as 'Partners-for-Profit', denoted by PfP, because it is a combination of a country's economic strategy resulting from its industry's position and the dependence on competent partners to realize it.

At about $88 \%$, the consistency of CP approximates a perfect subset relationship at a significant level, given the large number of observations. PfP even shows a consistency score of about $96 \%$, a value at which a perfect subset relationship is virtually achieved. It is almost always sufficient with respect to a high rate of membership. At a joint value of $92 \%$, this indicates that the two paths are also highly consistent over time.

However, consistency often works against coverage, which provides a measure of the empirical weight of the set-relational connection. ${ }^{24}$ Despite displaying high consistency scores, coverage for both solutions is far from trivial. The raw score of $\mathrm{CP}$, which does not take into account the overlap of variation in the outcome also accounted for by PfP, is about $28 \%$. This indicates an empirical magnitude that can certainly be considered substantial. PfP has a raw score of $47 \%$, which means

\footnotetext{
${ }^{24}$ Coverage is evaluated using the following formula: Coverage $\left(X_{i} \leqslant Y_{i}\right)=\sum\left[\min \left(X_{i}, Y_{i}\right)\right] / \sum Y_{i}$.
} 
(d)

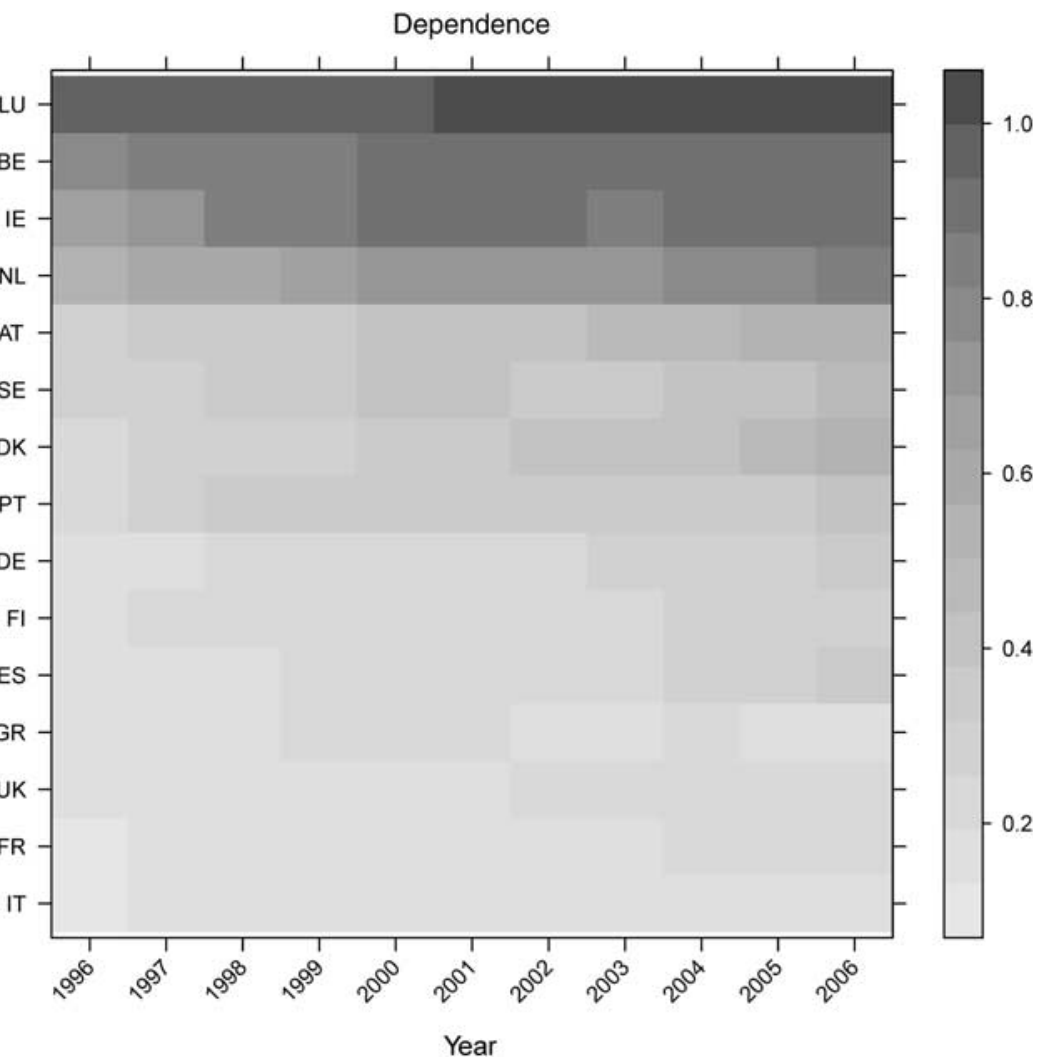

Figure 2 Continued

that the sum of outcome membership scores of the subset-consistent observations is almost covered by half. Given the higher consistency score, this underlines the higher empirical importance of PfP all the more. When treated as alternative paths, both solutions have a joint coverage score of about $62 \%$.

The relative empirical weight of PfP becomes even more pronounced when unique coverage scores are taken into account. As some cases conform to more than one combination of conditions, assessing unique coverage provides a way of disentangling their respective relative importance (Ragin, 2008: 63). The results show that almost half of the coverage that is due to CP is in fact covered by PfP, but only about a quarter of PfP's coverage is also due to CP. This suggests that the less complex combination may indeed be the empirically more important one. A qualitative investigation of this result is impossible within the scope of this article, but it certainly provides some general indication as to which combinatorial pathway may guide more detailed case analyses focusing on empirical weight. Countries with the potential to expand their prime systems export market share may find it easier to enter into such agreements with preferentially or functionally homogeneous countries. In essence, what economic cooperation in security matters 
(e)

Support

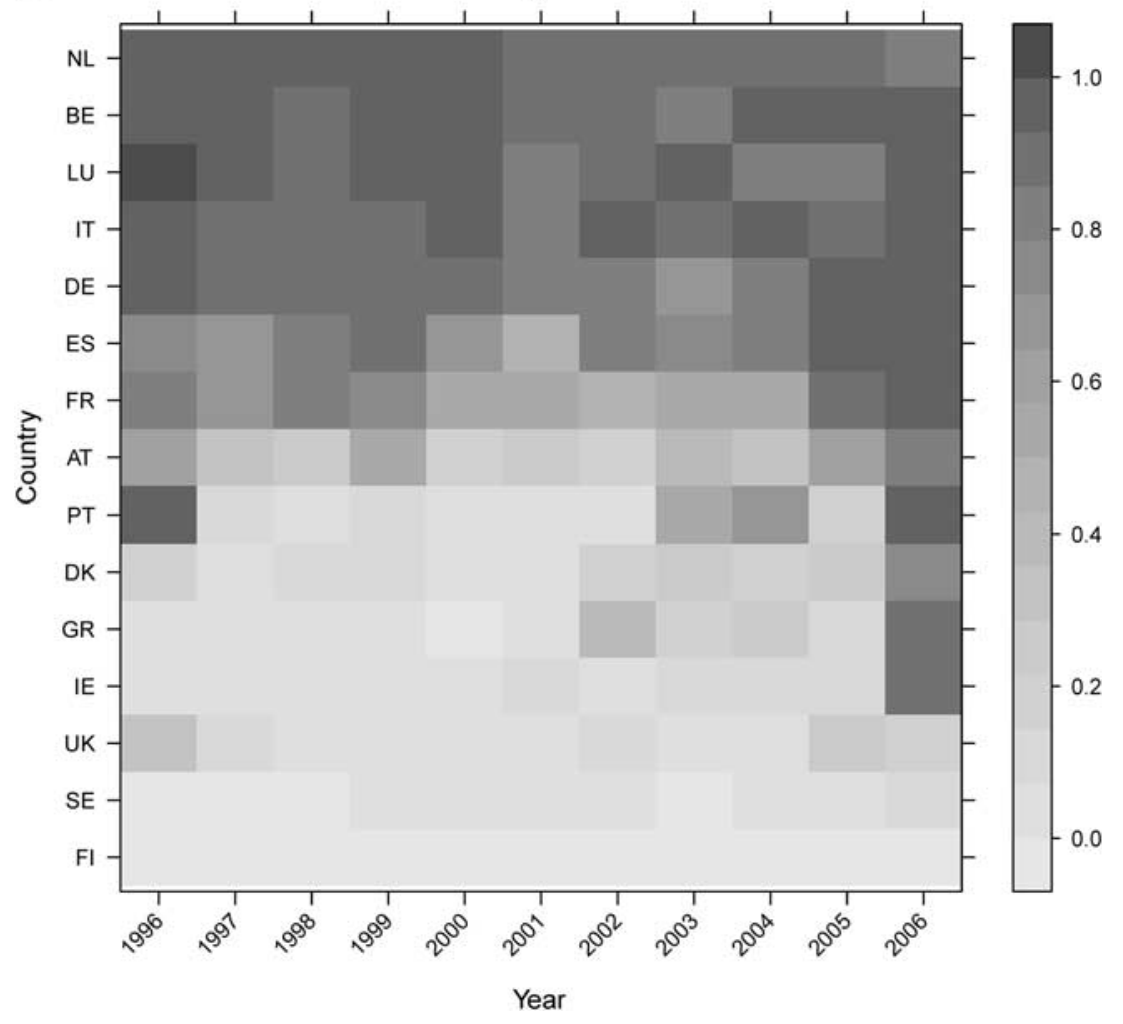

Figure 2 Continued

requires is a fair portion of confidence in partners' professional integrity and technical ability. It then comes as no surprise to see the Swedish Ministry of Defence (2004: 19) seeking to cooperate only with 'the most important countries as regards the international skills we need for our equipment supply'. Figure 3 visualizes the intermediate solution in panels $a$ and $b$. Panel $b$ in fact attests to Sweden's increasingly methodical involvement in armaments cooperation after the 1990s. In the case of Austria, the principle of neutrality clearly was an issue during the 1990s, but has been gradually hollowed out in recent years, politically as well as economically. ${ }^{25}$

CP presents a less simple path. High economic dependence indicates a low reservation point for international cooperation, which integrates with a propensity to

25 A specific provision in the Austrian Federal Constitution (Article 23f) accords precedence to decisions taken in the framework of CFSP over the Federal Constitutional Law on Austria's Permanent Neutrality. It was further amended to clarify that Austria's participation in Petersberg Task missions is not to be restricted by the Federal Constitutional Law. In the first half of 2011, Austria will for the first time contribute forces to EU Battle Groups. 
(f)

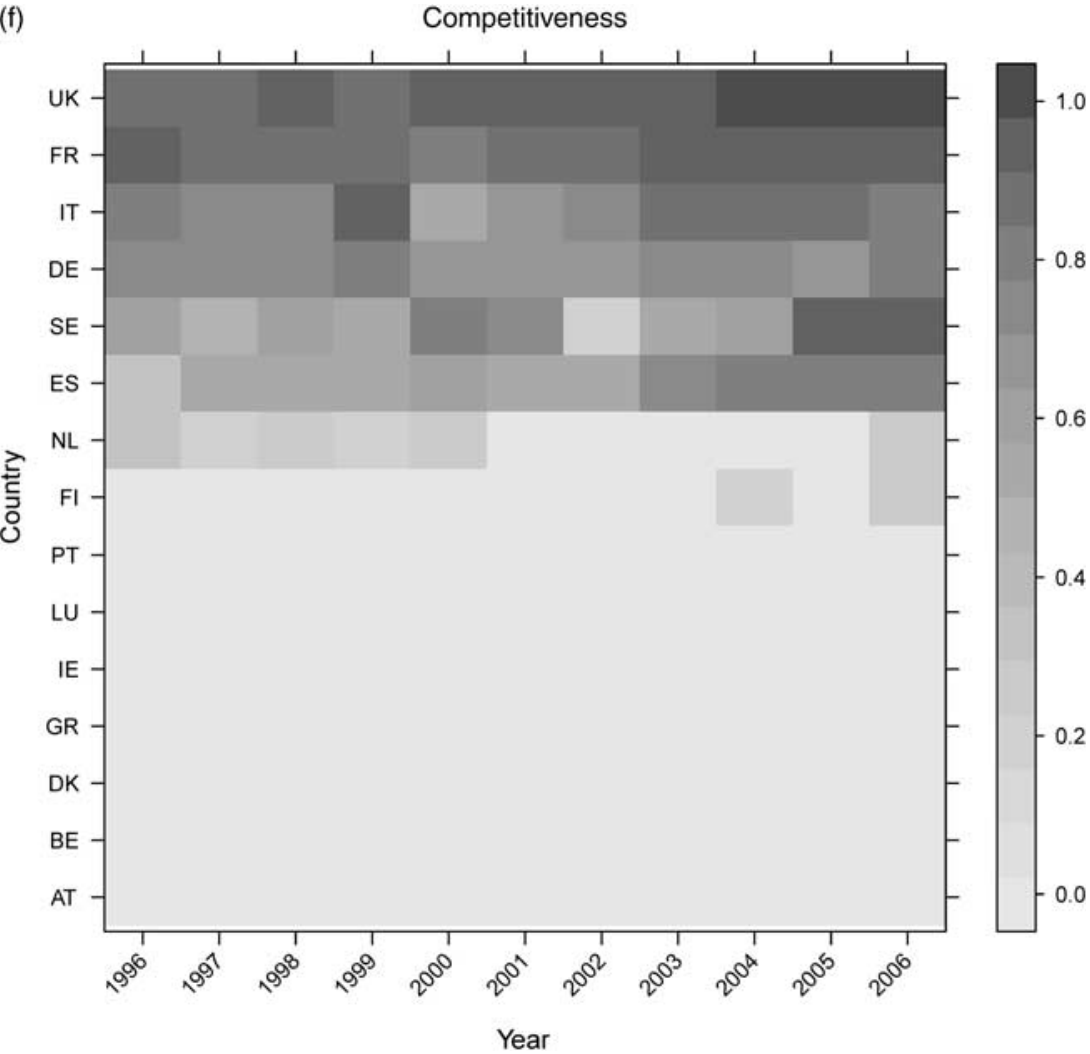

Figure 2 Continued

Table 1. Intermediate (IMT) and parsimonious solution (PMS) ${ }^{\mathrm{a}}$

\begin{tabular}{|c|c|c|c|c|c|c|}
\hline \multirow[b]{2}{*}{ Minimal formula } & \multicolumn{2}{|c|}{ Raw coverage } & \multicolumn{2}{|c|}{ Unique coverage } & \multicolumn{2}{|c|}{ Consistency } \\
\hline & IMT & PMS & IMT & PMS & IMT & PMS \\
\hline \multicolumn{7}{|l|}{ Dependence $\cap$ support $\cap$} \\
\hline homogeneity $\cap$ federalism & 0.284 & & 0.155 & & 0.886 & \\
\hline Competitiveness $\cap$ homogeneity & 0.470 & & 0.341 & & 0.965 & \\
\hline Competitiveness & & 0.514 & & 0.185 & & 0.965 \\
\hline Support $\cap$ federalism & & 0.527 & & 0.197 & & 0.891 \\
\hline \multicolumn{7}{|l|}{ Total } \\
\hline Frequency cut-off & \multicolumn{2}{|c|}{6} & & & & \\
\hline Consistency cut-off & \multicolumn{2}{|c|}{0.8} & & & & \\
\hline Solution coverage & 0.625 & 0.711 & & & & \\
\hline Solution consistency & 0.923 & 0.898 & & & & \\
\hline
\end{tabular}

a Simplifying assumptions for intermediate solution: present $=($ federalism, homogeneity, dependence, support, competitiveness); absent $=($ power $)$. 
delegate authority, here in the form of an indirect transfer of control over national armaments acquisition. When these conditions are supplemented by public support for joint action and preferential or functional homogeneity, the requirements for cooperation in an area as sensitive as armaments cooperation may be fulfilled. Though the two paths are quite disparate, the commonality of homogeneity is noticeable. In fact, it was the only condition in tests of necessity with a sufficiently high consistency level of $86 \%$.

Without this component, the empirical relevance of the remaining conditions may decline sharply. This can be tested by choosing a parsimonious solution instead of an intermediate one. Not only could the plausibility of the argument be significantly undermined, but coverage may also approach triviality, depending on the overlap of the subset-consistent cases in both solutions. That requires a less conservative strategy as far as the incorporation of logical remainders is concerned. ${ }^{26}$

In fact, only 10 of the 64 logically possible combinations contain over $90 \%$ of the data, and 48 of them hold no observations at all. A useful strategy in such a situation is to allow for counterfactual cases (Fearon, 1991; Tetlock and Belkin, 1996; Ragin, 2008). In contrast to the intermediate solution, a parsimonious solution takes easy as well as difficult counterfactuals into account. However, as each condition was hypothesized to contribute individually to the outcome without foreclosing combinations, causal implausibilities should not arise. For instance, the influence of business interests on policy is as likely in the absence of public support as it is in its presence (e.g. Jacobs and Page, 2005).

When allowing for easy as well as difficult counterfactuals, competitiveness is the reduction to PfP, but only in 30 of the 165 cases was homogeneity the constraining condition, resulting in similarity of the two paths as graphically revealed in panels $b$ and $c$ of Figure 3. Although the gains from cooperation may be reduced without homogeneity because additional collective control would be required to offset the absence of relational trust, this essentially means that business is the dominant component in the subset relation. As the UK Ministry of Defence (2005: 32) underlines, '[e]xports are an important part of the defence economic landscape'. ${ }^{27}$ Alternatively, support $\cap$ federalism is the reduction to $\mathrm{CP}^{28}$ This result lends weight to arguments that have been made by a number of scholars on the combined effect of public opinion and constitutional culture. Risse (1991) as well as Soroka and Wlezien (2005), for example, emphasize that the effect of public opinion on policy appears to be conditional on a country's constitutional design through which it is filtered.

\footnotetext{
${ }^{26}$ Logical remainders are combinations of conditions that are logically possible, but do not hold any cases for reasons of non-inclusion or non-existence.

27 Since homogeneity was the only condition with a significant consistency level in necessity tests, this path should be treated with some caution.

${ }^{28}$ Besides support $\cap$ federalism, support $\cap$ bomogeneity and federalism $\cap$ dependence are alternative, but redundant prime implicants.
} 
(a)

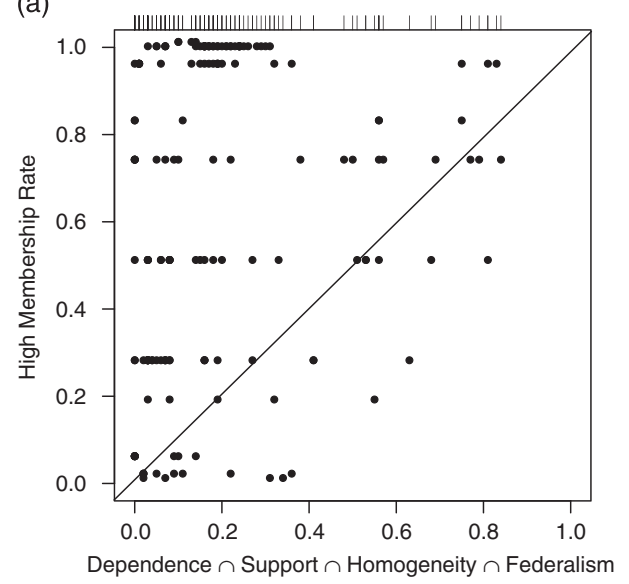

(c)

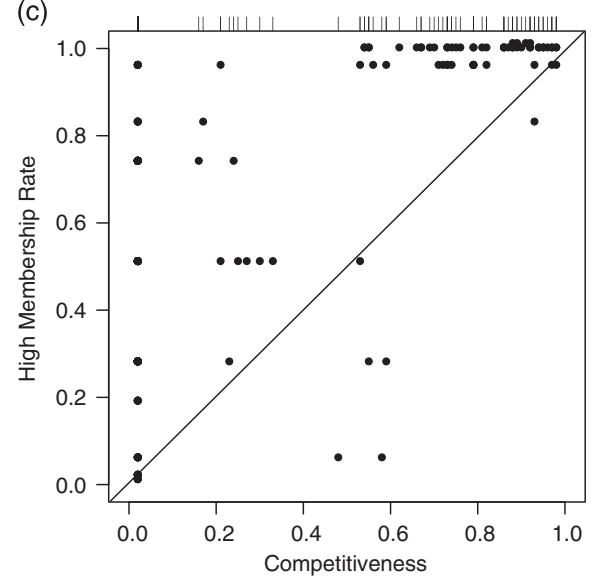

(b)

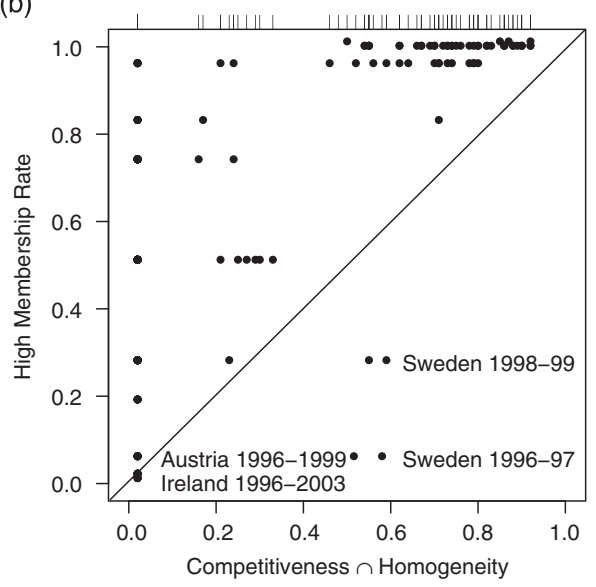

(d)

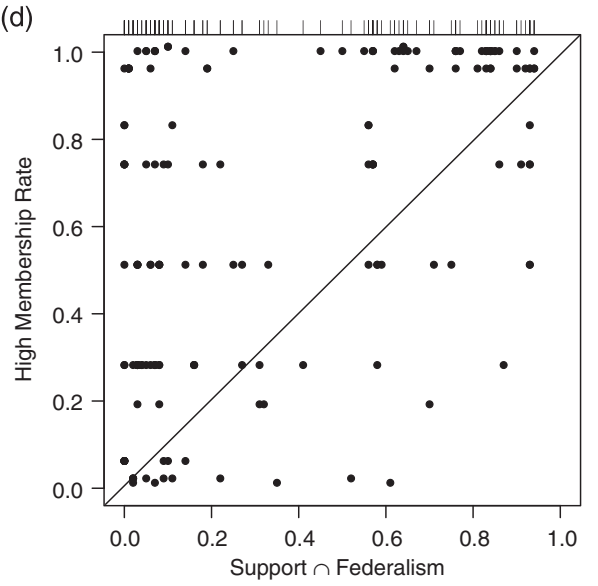

Figure 3 Intermediate Solution ( $\mathrm{a}$ and $\mathrm{b}$ ) and Parsimonious Solution ( $\mathrm{c}$ and $\mathrm{d}$ )

\section{Conclusion}

Which conditions are relevant in explaining why governments join international agreements in an area as potentially threatening to core national interests as armaments? Using fuzzy set qualitative comparative analysis, this article identified two distinct paths to cooperation in the EU for the years 1996-2006 that represent sufficient causal combinations. Equifinality involves diversity, and the results confirmed this fact through two distinct paths under which countries have joined formal agreements. Foremost among the reasons for states to do so were economic motives. This is reflected in the defence industrial strategies of many European governments. Technological advancement and the consolidation of the US armaments industry have put pressure on European countries to strengthen their defence industrial base if important export market shares are not to be lost. 
In addition, a competitive industrial base maintains and develops important technological skills, and generates employment and balance of payments benefits. However, the international division of production, the harmonization of weapons export procedures, and the sharing of knowledge are risky strategies, so participating governments want to make sure that their partners have the technological ability and professional integrity to create the theoretical basis for successful cooperation.

Alternatively, countries seem to enter into cooperation for reasons other than economically driven motives. A constitutional culture marked by federalist structures predisposes them to share control more willingly, and combines with public support for joint European action in defence matters, an open economy, and homogeneity to produce the conditions sufficient for active cooperation. These two diverse paths confirmed the advantages of applying a data-driven identification of relevant conditions. While five of the six perspectives received support to different degrees, in none of the combinations of conditions was a country's power differential in relation to the US component. Although this must not be interpreted as hard evidence against a Realist logic behind intergovernmental armaments cooperation in Europe, it certainly reduces its explanatory traction.

Intergovernmental cooperation on armaments is increasingly prioritized in European capitals. Initiatives inside and outside the EU framework will further shape the development of the European defence market on both the supply and the demand side in the years to come. Ongoing discussions about the incorporation of OCCAR into the European Defence Agency attest to this dynamic, which will not only affect those countries that have formed the population of this analysis. Pressures to restructure armaments procurement have also been high in Central and Eastern European countries. Their armed forces participate in international military missions along with Western European neighbours, but economic history did not produce the conditions conducive to the emergence of an internationally competitive armaments industry that could contribute much to EU-wide restructuring efforts apart from acting as vital export markets or niche system suppliers. In short, Central and East European governments are no ideal partners for profit. Whether they will choose to align themselves more closely with the United States, as Poland did in 2003 when it set the seal on one of the largest single military contracts negotiated in Europe after the end of the Cold War, involving the procurement of 48 Lockheed Martin F-16s instead of Saab's Gripen and Dassault's Mirage, or to participate readily in European fora may thus partly depend on the alternative combination of conditions identified in this article.

\section{Acknowledgements}

Earlier versions of this article were presented at two CIS workshops in October 2008 and February 2009, and at the 2010 Annual Conference of the Swiss Political Science Association. For helpful comments I am grateful to Gary Goertz, Mark Daniel Jäger, Dirk Leuffen, Wilhelm Mirow, Bianca Sarbu, Kaspar Schiltz, 


\author{
Frank Schimmelfennig, Guido Schwellnus, Manuel Suter, the three anonymous \\ reviewers, and Andreas Wenger.
}

\title{
References
}

Adler, E. and M.N. Barnett (1996), 'Governing anarchy: a research agenda for the study of security communities', Ethics \& International Affairs 10(1): 63-98.

Aldrich, J.H., C. Gelpi, P. Feaver, J. Reifler and K.T. Sharp (2006), 'Foreign policy and the electoral connection', Annual Review of Political Science 9(1): 477-502.

Aronson, E., T.D. Wilson and R.M. Akert (2007), Social Psychology, 6th edn., Upper Saddle River, NJ: Pearson Prentice-Hall.

Art, R.J. (1996), 'Why western europe needs the United States and NATO', Political Science Quarterly 111(1): 1-39.

- (2004), 'Europe hedges its security bets', in T.V. Paul, J.J. Wirtz and M. Fortmann (eds), Balance of Power: Theory and Practice in the 21st Century, Stanford: Stanford University Press, pp. 179-213.

- (2006), 'Striking the balance', International Security 30(3): 177-185.

Baldwin, D.A. (1980), 'Interdependence and power: a conceptual analysis', International Organization 34(4): 471-507.

Barros, C.P. (2002), 'Small countries and the consolidation of the European Defence Industry: Portugal as a case study', Defence \& Peace Economics 13(4): 311-319.

Bartels, L.M. (1991), 'Constituency opinion and congressional policy making: The Reagan Defense Build Up', The American Political Science Review 85(2): 457-474.

Baum, M.A. and P.B.K. Potter (2008), 'The relationships between mass media, public opinion, and foreign policy: toward a theoretical synthesis', Annual Review of Political Science 11(1): 39-65.

Bulmer, S.J. (1997), 'Shaping the rules? The constitutive politics of the European Union and German power', in P.J. Katzenstein (ed.), Tamed Power: Germany in Europe, Ithaca, NY: Cornell University Press, pp. 49-79.

Burstein, P. (2003), 'The impact of public opinion on public policy: a review and an agenda', Political Research Quarterly 56(1): 29-40.

Checkel, J.T. and A. Moravcsik (2001), 'A constructivist research program in EU Studies?', European Union Politics 2(2): 219-249.

Checkel, J.T. (2008), 'Process tracing', in A. Klotz and D. Prakash (eds), Qualitative Methods in International Relations: A Pluralist Guide, Basingstoke: Palgrave Macmillan, pp. 114-127.

Clark, T.D., J.M. Larson, J.N. Mordeson, J.D. Potter and M.J. Wierman (2008), Applying Fuzzy Mathematics to Formal Models in Comparative Politics, Berlin: Springer.

Clarke, K.A. (2005), 'The phantom menace: omitted variable bias in econometric research', Conflict Management and Peace Science 22(4): 341-352.

- (2009), 'Return of the Phantom Menace: omitted variable bias in political research', Conflict Management and Peace Science 26(1): 46-66.

Cornu, C. (2001), 'Fortress Europe - real or virtual?', in B. Schmitt (ed.), Between Cooperation and Competition: The transatlantic Defence Market, Paris: Western European Union Institute for Security Studies, pp. 51-92.

Crollen, E. (2003), 'Prospects for increased cooperation in European Defence industry policies', European Security 12(2): 89-98.

Domhoff, G.W. (2002), 'The power elite, public policy, and public opinion', in J. Manza, F.L. Cook and B.I. Page (eds), Navigating Public Opinion: Polls, Policy, and the Future of American Democracy, Oxford: Oxford University Press, pp. 124-137.

Eichenberg, R.C. (2000), 'NATO and European security after the cold war: will European citizens support a common security policy?', in B.L. Nacos, R.Y. Shapiro and P. Isernia (eds), Decisionmaking in a Glass House: Mass Media, Public Opinion, and American and European Foreign Policy in the 21st Century, Lanham: Rowman \& Littlefield, pp. 155-175. 
Eichenberg, R.C. and R. Stoll (2003), 'Representing defense: democratic control of the defense budget in the United States and Western Europe', The Journal of Conflict Resolution 47(4): 399-422.

Erikson, R.S., M. MacKuen and J.A. Stimson (2002), The Macro Polity, Cambridge: Cambridge University Press.

European Commission (1996), The Challenges Facing the European Defence-Related Industry, A Contribution for Action at European Level, Brussels: Commission of the European Communities, COM (1996) 10.

- (2007), Proposal for a Directive of the European Parliament and of the Council on the Coordination of Procedures for the Award of Certain Public Works Contracts, Public Supply Contracts and Public Service Contracts in the Fields of Defence and Security. COM (2007) 766.

Evans, P.B. (1993), 'Building an integrative approach to international and domestic politics: reflections and projections', in P.B. Evans, H.K. Jacobson and R.D. Putnam (eds), Double-Edged Diplomacy: International Bargaining and Domestic Politics, Berkeley, CA: University of California Press, pp. 397-430.

Fearon, J.D. (1991), 'Counterfactuals and hypothesis testing in political science', World Politics 43(2): 169-195.

Feld, S.L. (1982), 'Social structural determinants of similarity among associates', American Sociological Review 47(6): 797-801.

Gambetta, D. (1988), Trust: Making and Breaking Cooperative Relations, Oxford: Basil Blackwell.

Geller, D.S. (1993), 'Power differentials and war in rival dyads', International Studies Quarterly 37(2): 173-193.

George, A.L. and A. Bennett (2005), Case Studies and Theory Development in the Social Sciences, Cambridge, MA.: MIT Press.

Goertz, G. (2006), Social Science Concepts: A User's Guide, Princeton, NJ: Princeton University Press.

Gowa, J. (1989), 'Bipolarity, multipolarity, and free trade', The American Political Science Review 83(4): $1245-1256$.

Grieco, J.M. (1988), 'Anarchy and the limits of cooperation: a realist critique of the newest liberal institutionalism', International Organization 42(3): 485-507.

Hartley, K. (2006), 'Defence industrial policy in a military alliance', Journal of Peace Research 43(4): 473-489.

- (2008), 'Collaboration and European defence industrial policy', Defence \& Peace Economics 19(4): 303-315.

Hartley, T. and B. Russett (1992), 'Public opinion and the common defense: who governs military spending in the United States?', The American Political Science Review 86(4): 905-915.

Hasenclever, A., P. Mayer and V. Rittberger (1997), Theories of International Regimes, Cambridge: Cambridge University Press.

Hayward, K. (2001), 'The globalisation of defence industries', Survival 43(2): 115-132.

Holsti, O.R. (2004), Public Opinion and American Foreign Policy, Analytical Perspectives on Politics, Ann Arbor, MI: University of Michigan Press.

Hooghe, L. and G. Marks (2001), Multi-Level Governance and European Integration, Governance in Europe, Lanham: Rowman \& Littlefield Publishers.

Hooghe, L., G. Marks and A.H. Schakel (2008), 'Operationalizing regional authority: a coding scheme for 42 countries, 1950-2006', Regional \& Federal Studies 18(2): 123-142.

Howorth, J. (2007), Security and Defence Policy in the European Union, Basingstoke: Palgrave Macmillan. Huntington, S.P. (1993), 'Why international primacy matters', International Security 17(4): 68-83.

International Institute for Strategic Studies (1997-2007), The Military Balance (Various Years), London: Routledge.

Jachtenfuchs, M. (2002), Die Konstruktion Europas: Verfassungsideen und institutionelle Entwicklung, Baden-Baden: Nomos.

Jacobs, L.R. and B.I. Page (2005), 'Who influences U.S. foreign policy?', The American Political Science Review 99(1): 107-123.

James, A.D. (2001), 'The prospects for a transatlantic defence industry', in B. Schmitt (ed.), Between Cooperation and Competition: The transatlantic Defence Market, Paris: Western European Union Institute for Security Studies, pp. 93-122. 
Jervis, R. (2005), 'Understanding the Bush Doctrine', in G.J. Ikenberry (ed.), American Foreign Policy: Theoretical Essays, Boston, MA: Houghton Mifflin Company, pp. 576-599.

Jones, S.G. (2007), The Rise of European Security Cooperation, Cambridge: Cambridge University Press. Kant, I. and H.S. Reiss ([1975]1970), Kant's Political Writings, Cambridge: Cambridge University Press. Kapstein, E.B. (1991), 'International collaboration in armaments production: a second-best solution', Political Science Quarterly 106(4): 657-675.

- (2002), 'Allies and armaments', Survival 44(2): 141-155.

Keohane, D. and T. Valasek (2008), Willing and Able? EU Defence in 2020, London: Centre for European Reform.

Kernic, F., J. Callaghan and P. Manigart (2002), Public Opinion on European Security and Defense: A Survey of European Trends and Public Attitudes toward CFSP and ESDP, Frankfurt an Main: Peter Lang.

King, A. (2005), 'The future of the European Security and defence policy', Contemporary Security Policy 26(1): 44-61.

Kocs, S.A. (1995), Autonomy or Power? The Franco-German Relationship and Europe's Strategic Choices, 1955-1995, Westport: Praeger.

Koenig-Archibugi, M. (2004), 'Explaining government preferences for institutional change in EU Foreign and security policy', International Organization 58(1): 137-174.

Layne, C. (2003), 'America as European Hegemon', The National Interest 72: 17-30.

- (2006), 'The 'Poster Child for Offensive Realism': America as a global hegemon', Security Studies 12(2): $120-164$.

Legro, J.W. (1996), 'Culture and preferences in the international cooperation two-step', The American Political Science Review 90(1): 118-137.

Levine, J.M. and R.L. Moreland (1990), 'Progress in small group research', Annual Review of Psychology 41(1): 585-634.

Lewis, J. (2005), 'The Janus Face of Brussels: socialization and everyday decision making in the European Union', International Organization 59(4): 937-971.

Liberman, P. (1996), 'Trading with the enemy: security and relative economic gains', International Security 21(1): 147-175.

Lorell, M.A. and J. Lowell (1995), Pros and Cons of International Weapons Procurement Collaboration, Santa Monica: RAND.

Maoz, Z. (2004), 'Pacifism and Fightaholism in International politics: a structural history of national and dyadic conflict, 1816-1992', International Studies Review 6(4): 107-134.

Marks, G., L. Hooghe and A.H. Schakel (2008), 'Measuring regional authority', Regional \& Federal Studies 18(2): 111-121.

Mawdsley, J. (2000), The Changing Face of European Armaments Cooperation: Continuity and Change in British, French and German Armaments Policy 1990-2000. PhD thesis. Newcastle: School of Geography, Politics and Sociology, Newcastle University.

— (2008), 'European union armaments policy: options for small states?', European Security 17(2): $367-385$.

Mayer, R.C., J.H. Davis and F.D. Schoorman (1995), 'An integrative model of organizational trust', The Academy of Management Review 20(3): 709-734.

Mearsheimer, J.J. (1990), 'Back to the future: instability in Europe after the Cold War', International Security 15(1): 5-56.

- (2001), The Tragedy of Great Power Politics, New York: W.W. Norton.

Mérand, F. (2008), European Defence Policy: Beyond the Nation State, Oxford: Oxford University Press.

Mill, J.S. ([1865]2007), Considerations on Representative Government C.V. Shields (eds). Marietta: Cherokee Publishing.

Monroe, A.D. (1979), 'Consistency between public preferences and national policy decisions', American Politics Research 7(1): 3-19.

— (1998), 'Public opinion and public policy, 1980-1993', The Public Opinion Quarterly 62(1): 6-28.

Moravcsik, A. (1991), 'Arms and Autarky in modern European History', Daedalus 120(4): 23-45. 
(1993a), 'Armaments among Allies: Franco-German weapons collaboration, 1975-1985', in P.B. Evans, H.K. Jacobson and R.D. Putnam (eds), Double-Edged Diplomacy: International Bargaining and Domestic Politics, Berkeley, CA: University of California Press, pp. 128-168.

- (1993b), 'Preferences and power in the European Community: a liberal intergovernmentalist approach', Journal of Common Market Studies 31(4): 473-524.

- (1997), 'Taking preferences seriously: a liberal theory of international politics', International Organization 51(4): 513-553.

Mörth, U. and M. Britz (2004), 'European integration as organizing: the case of armaments', Journal of Common Market Studies 42(5): 957-973.

Mullen, B. and C. Copper (1994), 'The relation between group cohesiveness and performance: an integration', Psychological Bulletin 115(2): 210-227.

Neal, D.J. and T. Taylor (2001), 'Globalisation in the defence industry: an exploration of the paradigm for US and European defence firms and the implications for being global players', Defence \& Peace Economics 12(4): 337-338.

Nickerson, R.S. (1998), 'Confirmation bias: a ubiquitous phenomenon in many guises', Review of General Psychology 2(2): 175-220.

Nincic, M. (1990), 'US Soviet policy and the electoral connection', World Politics 42(3): 370-396.

Organski, A.F.K. and J. Kugler (1980), The War Ledger, Chicago, IL: University of Chicago Press.

Page, B.I. and R.Y. Shapiro (1983), 'Effects of public opinion on policy', The American Political Science Review 77(1): 175-190.

Papayoanou, P.A. (1997), 'Economic interdependence and the balance of power', International Studies Quarterly 41(1): 113-140.

Paul, T.V. (2004), 'Introduction', in T.V. Paul, J.J. Wirtz and M. Fortmann (eds), Balance of Power: Theory and Practice in the 21st Century, Stanford: Stanford University Press, pp. 1-25.

Posen, B.R. (2006), 'European Union security and defense policy: response to unipolarity?', Security Studies 15(2): 149-186.

Putnam, R.D. (1988), 'Diplomacy and domestic politics: the logic of two-level games', International Organization 42(3): 427-460.

Ragin, C.C. (2000), Fuzzy-Set Social Science, Chicago, IL: University of Chicago Press.

Ragin, C.C., K.A. Drass and S. Davey (2006), Fuzzy-Set/Qualitative Comparative Analysis 2.0, Tucson, AZ: Department of Sociology, University of Arizona.

Ragin, C.C. (2008), Redesigning Social Inquiry: Fuzzy Sets and Beyond, Chicago, IL: University of Chicago Press.

Risse, T. (1991), 'Public opinion, domestic structure, and foreign policy in liberal democracies', World Politics 43(4): 479-512.

- (2005), 'Neofunctionalism, European Identity, and the Puzzles of European Integration', Journal of European Public Policy 12(2): 291-309.

Rittberger, B. (2005), Building Europe's Parliament: Democratic Representation beyond the NationState, Oxford: Oxford University Press.

Ruggie, J.G. (1998), 'What makes the world hang together? Neo-utilitarianism and the social constructivist challenge', International Organization 52(4): 855-885.

Schmitt, B. (2000), 'From Cooperation to Integration: Defence and Aerospace Industries in Europe', Paris: European Union Institute for Security Studies.

- (2003), The European Union and Armaments: Getting a Bigger Bang for the Euro, Chaillot Papers, Paris: European Union Institute for Security Studies.

Schneider, C.Q. and C. Wagemann (2006), 'Reducing complexity in Qualitative Comparative Analysis (QCA): remote and proximate factors and the consolidation of democracy', European Journal of Political Research 45(5): 751-786.

Singer, J.D., S. Bremer and J. Stuckey (1972), 'Capability distribution, uncertainty, and major power war, 1820-1965', in B. Russett (ed.), Peace, War, and Numbers, Beverly Hills, CA: SAGE Publications, pp. 19-48.

Singer, J.D. (1988), 'Reconstructing the correlates of war dataset on material capabilities of states, 1816-1985', International Interactions 14(2): 115-132. 
Skaperdas, S. and C. Syropoulos (2001), 'Guns, butter, and openness: on the relationship between security and trade', The American Economic Review 91(2): 353-357.

Soroka, S.N. and C. Wlezien (2005), 'Opinion-policy dynamics: public preferences and public expenditure in the United Kingdom', British Journal of Political Science 35(4): 665-689.

Soysa, de I., J.R. Oneal and Y.-H. Park (1997), 'Testing power-transition theory using alternative measures of national capabilities', The Journal of Conflict Resolution 41(4): 509-528.

Starr, H. (2005), 'Cumulation from proper specification: theory, logic, research design, and 'Nice' laws', Conflict Management and Peace Science 22(4): 353-363.

Stockholm International Peace Research Institute (1997-2007), Yearbook (Various Years): Armaments, Disarmament and International Security, Oxford: Oxford University Press.

Swedish Ministry of Defence (2004), Our Future Defence - The Focus of Swedish Defence Policy 2005-2007, Stockholm: Swedish Ministry of Defence.

Sweeney, K. and P. Fritz (2004), 'Jumping on the Bandwagon: an interest-based explanation for great power alliances', The Journal of Politics 66(2): 428-449.

Taylor, P. (1982), 'Weapons standardization in NATO: collaborative security or economic competition?', International Organization 36(1): 95-112.

Taylor, T. (1990), 'Defence industries in international relations', Review of International Studies 16(1): $59-73$.

Tetlock, P.E. and A. Belkin (eds) (1996), Counterfactual Thought Experiments in World Politics: Logical, Methodological, and Psychological Perspectives, Princeton, NJ: Princeton University Press.

Tonra, B. (2003), 'Constructing the CFSP: the utility of a cognitive approach', Journal of Common Market Studies 41(4): 731-756.

Törnqvist, S. (2001), 'Demand side collaboration and multinational procurement', The RUSI Journal 146(2): 63-68.

Tucker, J.B. (1991), 'Partners and rivals: a model of international collaboration in advanced technology', International Organization 45(1): 83-120.

UK Ministry of Defence (2005), Defence Industrial Strategy: Defence White Paper, London: UK Ministry of Defence.

Wagner, W. (2002), 'The subnational foundations of the European Parliament', Journal of International Relations \& Development 5(1): 24-37.

Wallace, W. (1986), 'What price independence? Sovereignty and interdependence in British Politics', International Affairs 62(3): 367-390.

Walt, S.M. (1985), 'Alliance formation and the balance of world power', International Security 9(4): 3-43.

(2005), Taming American Power: The Global Response to US Primacy, New York: W. W. Norton.

Waltz, K.N. (1959), Man, the State and War: A Theoretical Analysis, New York: Columbia University Press.

- (2000), 'Structural realism after the cold war', International Security 25(1): 5-41.

- (2008), Realism and International Politics, London: Routledge.

Wendt, A. (1995), 'Constructing international politics', International Security 20(1): 71-81.

- (1999), Social Theory of International Politics, Cambridge: Cambridge University Press.

- (2000), 'On the via media: a response to the critics', Review of International Studies 26(1): $165-180$.

Wiener, A. (2003), 'Constructivism: the limits of bridging gaps', Journal of International Relations \& Development 6(3): 252-275.

Williams, M. (2001), 'In whom we trust: group membership as an affective context for trust development', The Academy of Management Review 26(3): 377-396.

Wlezien, C. (2004), 'Patterns of representation: dynamics of public preferences and policy', The Journal of Politics 66(1): 1-24.

Wohlforth, W.C. (1999), 'The stability of a unipolar world', International Security 24(1): 5-41.

World Bank (2008), World Development Indicators, Washington, DC: The World Bank Group.

World Steel Association (2009), Crude steel statistics 2009. Retrieved 13 January 2009 from http:// www.worldsteel.org/index.php. 


\section{Appendix}

Table A1. Partial truth table

\begin{tabular}{|c|c|c|c|c|c|c|c|c|c|c|}
\hline Federalism & Homogeneity & Power & Competitiveness & Support & Dependence & Membership & Number & Consistency & PRE & Product \\
\hline 1 & 1 & 0 & 1 & 1 & 0 & 1 & 33 & 0.994 & 0.994 & 0.988 \\
\hline 0 & 1 & 0 & 1 & 0 & 0 & 1 & 10 & 0.970 & 0.961 & 0.933 \\
\hline 0 & 1 & 1 & 1 & 0 & 0 & 1 & 9 & 0.891 & 0.850 & 0.758 \\
\hline 1 & 1 & 1 & 0 & 1 & 1 & 1 & 20 & 0.875 & 0.768 & 0.672 \\
\hline 0 & 0 & 1 & 0 & 1 & 1 & 0 & 8 & 0.775 & 0.473 & 0.366 \\
\hline 1 & 1 & 1 & 0 & 0 & 0 & 0 & 6 & 0.774 & 0.519 & 0.402 \\
\hline 0 & 1 & 1 & 0 & 0 & 0 & 0 & 39 & 0.712 & 0.496 & 0.353 \\
\hline 0 & 1 & 1 & 0 & 0 & 1 & 0 & 10 & 0.669 & 0.358 & 0.239 \\
\hline
\end{tabular}

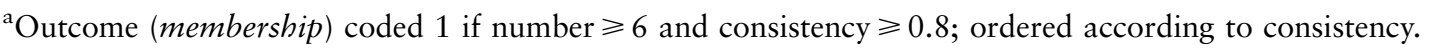


Table A2. Recalibration values ${ }^{\mathrm{a}}$

\begin{tabular}{|c|c|c|c|c|c|c|c|c|c|c|c|}
\hline Condition/years & 1996 & 1997 & 1998 & 1999 & 2000 & 2001 & 2002 & 2003 & 2004 & 2005 & 2006 \\
\hline \multicolumn{12}{|l|}{ Membership } \\
\hline$\alpha_{\mathrm{NM}}$ & 1.0 & 1.0 & 1.0 & 1.0 & 1.0 & 1.0 & 1.0 & 1.0 & 1.0 & 1.0 & 1.0 \\
\hline$\alpha_{\mathrm{CO}}$ & 2.0 & 2.0 & 2.5 & 2.5 & 2.5 & 2.5 & 2.5 & 2.5 & 3.0 & 3.0 & 3.0 \\
\hline$\alpha_{\mathrm{FM}}$ & 3.0 & 3.0 & 4.0 & 4.0 & 4.0 & 4.0 & 4.0 & 4.0 & 5.0 & 5.0 & 5.0 \\
\hline \multicolumn{12}{|l|}{ Federalism } \\
\hline$\alpha_{\mathrm{NM}}$ & 1.6 & 1.6 & 1.6 & 1.6 & 1.6 & 1.6 & 1.6 & 1.6 & 1.6 & 1.6 & 1.6 \\
\hline$\alpha_{\mathrm{CO}}$ & 12.6 & 12.6 & 12.7 & 12.8 & 12.8 & 12.9 & 13.0 & 13.0 & 13.1 & 13.1 & 13.1 \\
\hline$\alpha_{\mathrm{FM}}$ & 30.5 & 30.5 & 30.5 & 30.5 & 30.5 & 30.5 & 30.5 & 30.5 & 30.5 & 30.5 & 30.5 \\
\hline \multicolumn{12}{|l|}{ Homogeneity } \\
\hline$\alpha_{\mathrm{NM}}$ & 5 & 5 & 5 & 5 & 5 & 5 & 6 & 6 & 6 & 6 & 6 \\
\hline$\alpha_{\mathrm{CO}}$ & 38 & 39 & 39 & 41 & 42 & 44 & 46 & 48 & 50 & 51 & 51 \\
\hline$\alpha_{\mathrm{FM}}$ & 83 & 83 & 83 & 83 & 83 & 83 & 98 & 98 & 98 & 98 & 98 \\
\hline \multicolumn{12}{|l|}{ Power } \\
\hline$\alpha_{\mathrm{NM}}$ & 0.28 & 0.28 & 0.28 & 0.28 & 0.28 & 0.28 & 0.28 & 0.28 & 0.28 & 0.28 & 0.28 \\
\hline$\alpha_{\mathrm{CO}}$ & 0.36 & 0.36 & 0.36 & 0.36 & 0.36 & 0.36 & 0.36 & 0.36 & 0.36 & 0.36 & 0.36 \\
\hline$\alpha_{\mathrm{FM}}$ & 0.39 & 0.39 & 0.39 & 0.39 & 0.39 & 0.39 & 0.39 & 0.40 & 0.40 & 0.40 & 0.41 \\
\hline \multicolumn{12}{|l|}{ Dependence } \\
\hline$\alpha_{\mathrm{NM}}$ & 0.0 & 0.0 & 0.0 & 0.0 & 0.0 & 0.0 & 0.0 & 0.0 & 0.0 & 0.0 & 0.0 \\
\hline$\alpha_{\mathrm{CO}}$ & 0.5 & 0.5 & 0.5 & 0.5 & 0.5 & 0.5 & 0.5 & 0.5 & 0.5 & 0.5 & 0.5 \\
\hline$\alpha_{\mathrm{FM}}$ & 1.0 & 1.0 & 1.0 & 1.0 & 1.0 & 1.0 & 1.0 & 1.0 & 1.0 & 1.0 & 1.0 \\
\hline \multicolumn{12}{|c|}{ Support (net percentage figures) } \\
\hline$\alpha_{\mathrm{NM}}$ & -33.3 & -33.3 & -33.3 & -33.3 & -33.3 & -33.3 & -33.3 & -33.3 & -33.3 & -33.3 & -33.3 \\
\hline$\alpha_{\mathrm{CO}}$ & 0.0 & 0.0 & 0.0 & 0.0 & 0.0 & 0.0 & 0.0 & 0.0 & 0.0 & 0.0 & 0.0 \\
\hline$\alpha_{\mathrm{FM}}$ & 33.3 & 33.3 & 33.3 & 33.3 & 33.3 & 33.3 & 33.3 & 33.3 & 33.3 & 33.3 & 33.3 \\
\hline \multicolumn{12}{|c|}{ Competitiveness (constant 2000 US\$ millions) } \\
\hline$\alpha_{\mathrm{NM}}$ & 127 & 127 & 127 & 127 & 127 & 127 & 127 & 127 & 127 & 127 & 127 \\
\hline$\alpha_{\mathrm{CO}}$ & 589 & 576 & 567 & 565 & 557 & 551 & 543 & 543 & 548 & 556 & 568 \\
\hline$\alpha_{\mathrm{FM}}$ & 2026 & 2026 & 2026 & 2026 & 2026 & 2026 & 2026 & 2026 & 2026 & 2026 & 2026 \\
\hline
\end{tabular}

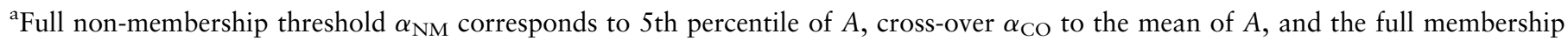
threshold $\alpha_{\mathrm{FM}}$ to the 95th percentile of $A$, except dependence and support which are externally defined. 